University of Redlands

\title{
Montclair High School: A Multi-dimensional GIS Approach to Tactical Emergency Response
}

\footnotetext{
A Major Individual Project submitted in partial satisfaction of the requirements for the degree of Master of Science in Geographic Information Systems

by

Howard Russell Johnson
}

Maxwell Baber, Ph.D., Chair

Mark P. Kumler, Ph.D.

December 2008 
Montclair High School: A Multi-dimensional GIS Approach to Tactical Emergency Response

Copyright $\odot 2008$

by

Howard Russell Johnson 
The report of Howard Russell Johnson is approved.

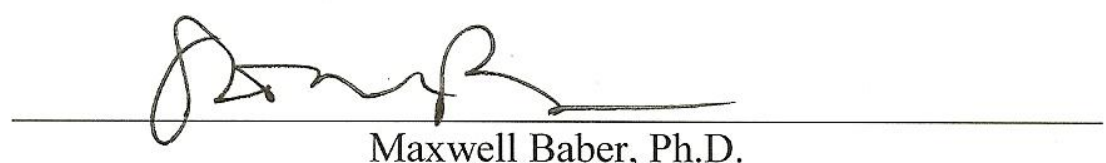

Maxwell Baber, Ph.D.

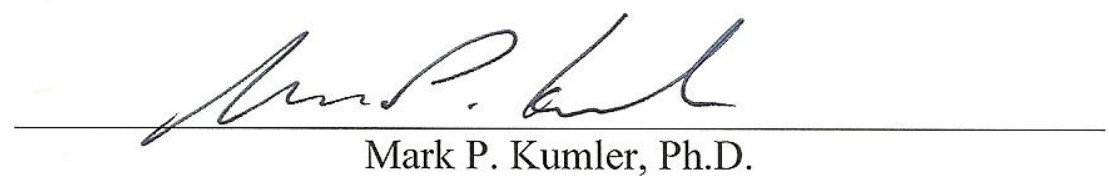

December 2008 



\section{ACKNOWLEDGEMENTS}

First things first, I must give thanks to my beautiful bride, Jeanelle, for all of her support over the past twelve months. Thank you for putting up with me and encouraging me to accomplish my goals through thick and thin. It was a tough year for you, but I couldn't have gotten by without you. Thanks and I love you.

Also, a big thank you to our unborn child, who not once left us with a dull moment, yet indirectly provided me with the encouragement to complete my project. Thanks Baby J!

I would like to thank my advisor Dr. Max Baber for all his positive encouragement throughout the MIP process. Thanks for the support throughout the entire year. And thank you to all of the MS GIS program staff for all of the fun times. I learned a great deal and at the same time had an enjoyable experience!

Very special thanks to Uncle Sam and the National Geospatial-Intelligence Agency (NGA) for providing me the opportunity to get a master's degree at the University of Redlands. I guess I owe you one, or three!

Thank you to my client, Steve Dague, and to the City of Montclair, California, for providing me with an excellent project idea.

Finally, I want to thank all of the new friends I acquired over the past twelve months in Redlands, California. Thanks to Almamy, Chris, Jerry, Kevin, Mandeep, Mike, Nate, and Rachel. We definitely have some memories to take away from this place. What a ride! 



\begin{abstract}
An Emergency Response Field Application

for Montclair High School, Montclair, California
\end{abstract}

by

Howard Russell Johnson

"This marks the fourth shooting incident at a U.S. school within a week -- the second at a college or university -- and serves as a stunning reminder that it is impossible to know when and where violence will occur." (Knapp, 02/15/2008)

This quote, referencing the 2008 shooting at Northern Illinois University, is a stark reminder that the school systems in the United States are soft targets for acts of violence. Although it is almost impossible to predict such tragic events, it is possible to prepare, react, and respond to these actions in a timely manner to reduce loss of life and property. Advances in technology, particularly in geographic information systems (GIS), have given first responders the ability to respond to these occurrences more rapidly and efficiently. The GIS application created in this project supports the needs of first responders to enhance preparation and response to emergencies, in this case at Montclair High School, Montclair, California. Utilizing a variety of geospatial tools and software applications, the system will provide emergency personnel with a unique application or system designed to support a more effective and efficient response. 



\section{Table of Contents}

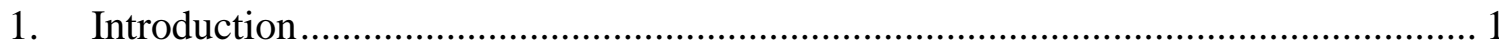

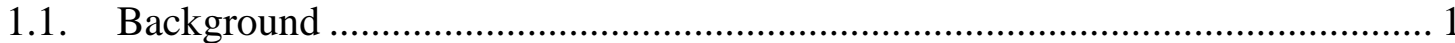

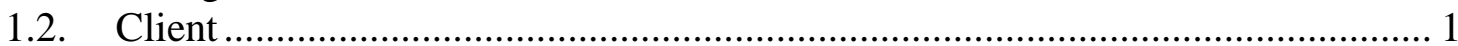

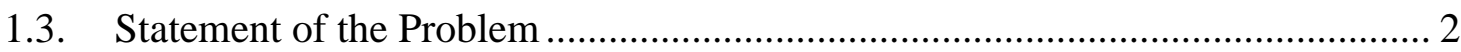

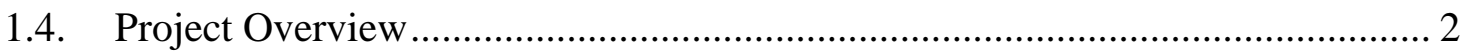

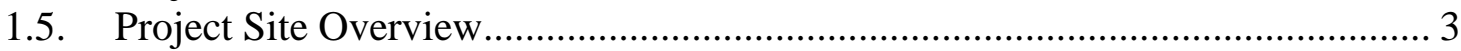

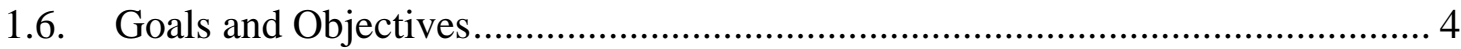

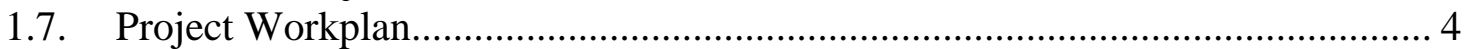

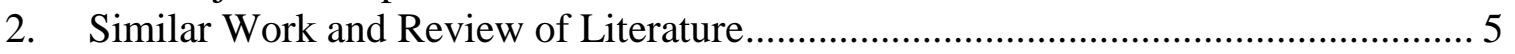

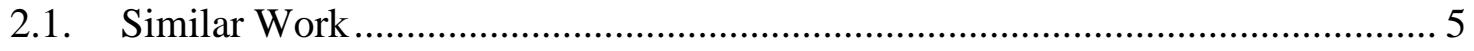

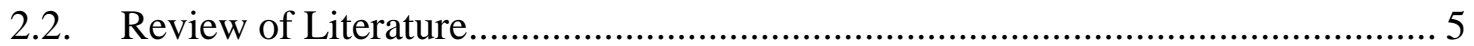

3. Methods, Feasibility Analysis, Requirements, and Design ........................................ 9

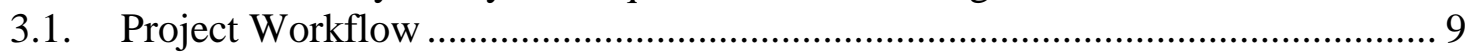

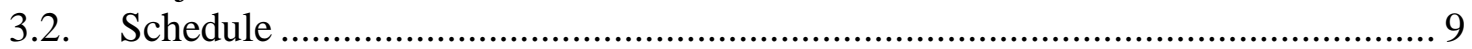

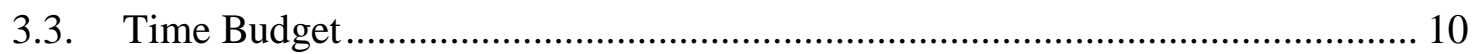

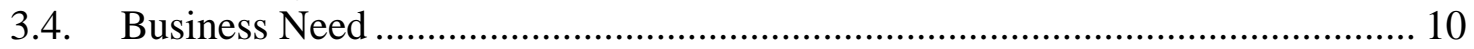

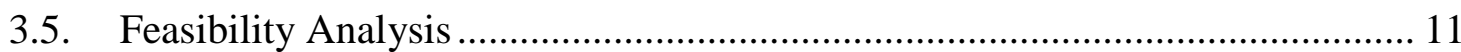

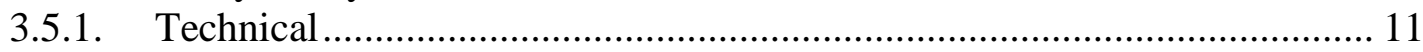

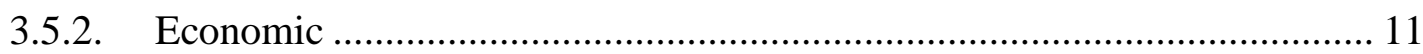

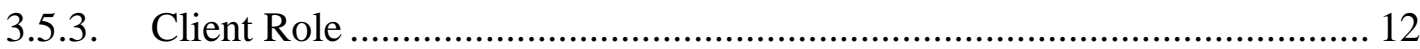

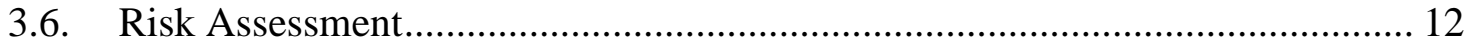

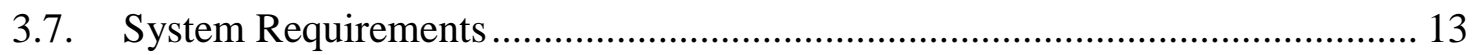

3.8. System Architecture ……………........................................................... 14

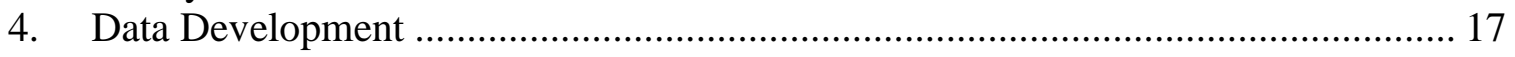

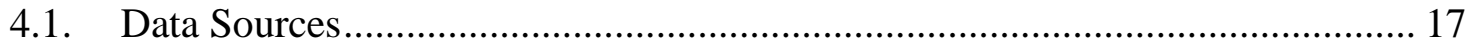

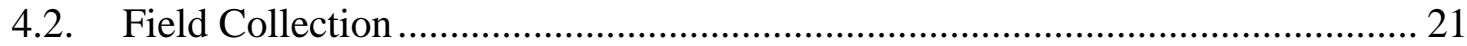

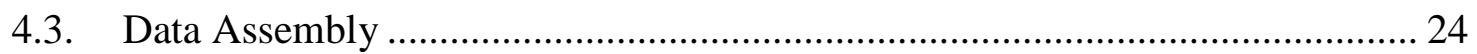

5. Project Development, Testing, and Deployment ………………………………..... 27

5.1. Project Assembly and Development ............................................................ 27

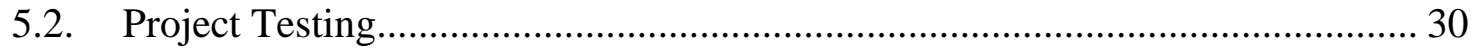

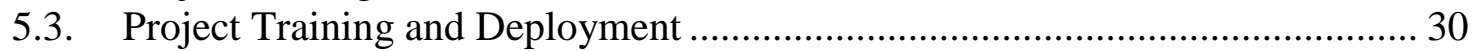

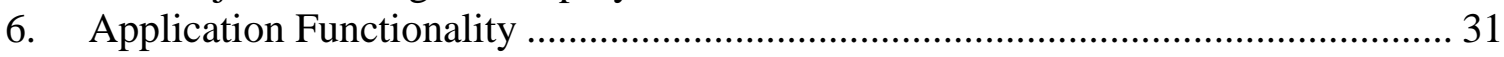

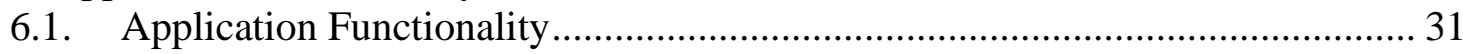

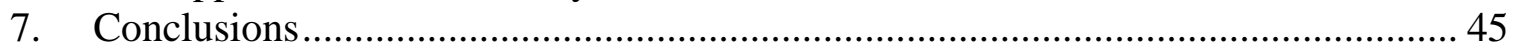

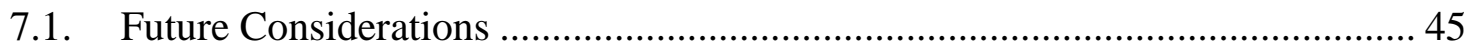

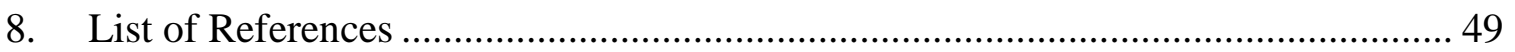

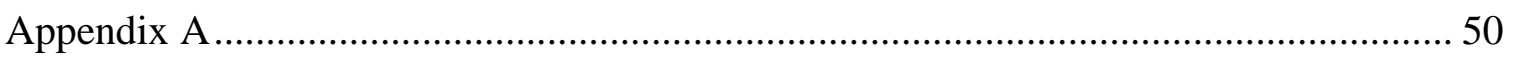




\section{List of Figures}

Figure 1. Reproduced map of Montclair High School, Montclair, CA ............................ 3

Figure 2. Project workflow diagram A ……………................................................. 4

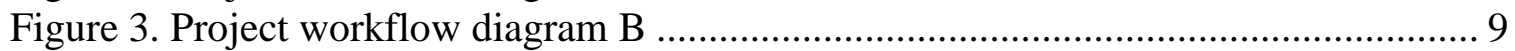

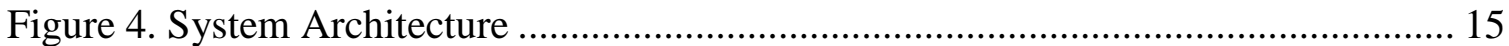

Figure 5. Aerial Photography of Montclair High School and surrounding environment. 18

Figure 6. Parcel data shapefile for neighborhood surrounding campus............................ 19

Figure 7. Reference map of the Montclair High School.................................................. 20

Figure 8. Example of CAD drawing used in application............................................... 21

Figure 9. Trimble GeoXH (left) and Ricoh Geo-Imaging digital camera (right) ............. 22

Figure 10. Specialized camera lens used for photo collection.......................................... 23

Figure 11. Conversion of $360^{\circ}$ photo (top left) into a QuickTime viewable format ........ 24

Figure 12. Montclair High School GIS toolkit file geodatabase …………………......... 25

Figure 13. Largest feature dataset in the Montclair High School geodatabase ................ 26

Figure 14. Five main layers of information for application............................................. 27

Figure 15. Point symbology for the Exterior Features layer......................................... 28

Figure 16. Point symbology for the Interior Features layer........................................... 28

Figure 17. Customized toolbar designed for application .............................................. 29

Figure 18. Example of the DVD with application submitted to the client ...................... 30

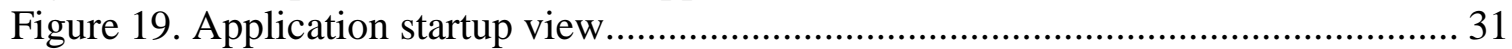

Figure 20. Customized toolbar designed for application ............................................. 32

Figure 21. Two-step process to view information of Perimeter Road View .................... 33

Figure 22. Two-step process to view information of Exterior Point of Entry (Gate)....... 34

Figure 23. Two-step process to view information of Exterior Point of Entry (Doorway) 34

Figure 24. Two-step process to view information of Exterior Utilities View .................. 35

Figure 25. Two-step process to view information of Exterior 360 View ......................... 36

Figure 26. Process of selecting Interior 360 View by hyperlink tool .............................. 37

Figure 27. Two-step process of obtaining information of Interior Hallway 360 View .... 38

Figure 28. Two-step process of obtaining information of Stairs View ............................ 39

Figure 29. Selection of facility polygon to reveal identify box ........................................ 40

Figure 30. CAD drawing layer is activated to reveal building drawing ........................... 41

Figure 31. Air Photo layer activation reveals photo of high school and surroundings..... 42

Figure 32. Google Earth 3D perspective of the Montclair High School .......................... 43

Figure 33. Zoomed in 3D perspective of Montclair High School ................................... 44

Figure 34. Example of Google ${ }^{\mathrm{TM}}$ SketchUp interior capabilities ....................................... 46

Figure 35. White marking on 0-360 lens for collection purposes..................... 47

Appendix Figure 1. Gantt Chart............................................... 57

Appendix Figure 2. Visual Basic code for the Google ${ }^{\mathrm{TM}}$ Earth link ................... 58 


\section{List of Tables}

Table 1. Time Budget..................................................... 10

Table 2. Risk Assessment.................................................... 12

Table 3. System Functional Requirements..................................... 13

Table 4. System Non-Functional Requirements.................................. 14 


\section{List of Acronyms}

CAD Computer-Aided Design

ESRITM Environmental Systems Research Institute Inc.

GIS Geographic Information System(s)

MIP Major Individual Project

MS GIS Master of Science in Geographic Information Systems

POC Point of Contact

POI Point of Interest

SOP Standard Operating Procedures

SWAT Special Weapons and Tactics

$2 \mathrm{D}$

Two-Dimensional

3D Three-Dimensional 


\section{Introduction}

Today, more than ever before, terrorism, gun violence, and natural disasters present emergency personnel with tremendous challenges. Any one of these events requires intense and immediate action. Without an effectively designed response plan to react to a hostage situation or bomb threat, emergency personnel face a greater likelihood of casualties or increased destruction. It is imperative that personnel be equipped with an application that provides the much needed information to enhance the timeliness of their response.

The purpose of this project is to design a GIS model to help first responders prepare, plan, and react to emergencies. This model will be able to function in other environments; however for the purpose of this project, a local high school served as the study area.

The police and fire departments in the City of Montclair, California were in need of such a tool to plan for and react to potential events at the Montclair High School. This paper addresses the aforementioned problem and presents a solution using GIS technology to assist Montclair first responders.

\subsection{Background}

Society today is presented with various threats to our environment. It is more exposed to the harsh reality of terrorism, increased levels of crime, and the potential for natural disaster or environmental hazards in our towns and cities. This danger presents our emergency response personnel with an important question; are emergency responders prepared to respond to a crisis? In the event of threat or disaster, it is extremely important that law enforcement, firefighters, and emergency personnel maintain up-todate contingency and evacuation planning for significant individual facilities, as well as entire towns and cities.

In recent years schools have become prime targets. Globally and particularly in the United States, various threats in school systems have become all too common in headlines during the past decade. The shootings at Columbine and Foss High Schools, Virginia Polytechnic Institute and State University and Northern Illinois University, and the terrorist/hostage attack at the Beslan School in Beslan, Russia, are a few of the more devastating events in recent years. The emergency response for a number of these events received criticism for inefficient response.

\subsection{Client}

The client and primary point of contact (POC) for this project was Steven Dague, GIS Specialist for the City of Montclair, California. In addition to Mr. Dague, two additional people served as secondary clients and were integral parts of the project. Montclair Police Officer David Taylor, assigned to Montclair High School, provided the expertise in law enforcement and emergency response. Mr. Larry Tisdale, Montclair High School 
Vice Principal and high school building manager, provided access to the high school, facility information, and contacts within the high school.

At the initial meeting, Mr. Dague and high ranking officials from the City of Montclair fire and police departments expressed the need for a tool to enhance response to an emergency situation at the high school. When discussing their project request, the representatives from both fire and police departments referenced a previous Major Individual Project (MIP) completed by Mr. Thomas Baker of the University of Redlands MS GIS Program in 2007, which addressed a similar topic for the Montclair Plaza shopping center. They further mentioned that a continuation of the previous MIP could serve as a potential baseline for a product in support of the Montclair High School (Baker, 2007; S. Dague, MIP interview and discussion, January 23, 2008). They requested a customized, interactive GIS application to support emergency responders with critical facility information in an efficient, easy-to-use manner. The project could provide the user with multi-dimensional perspectives of the site by using aerial photography, computer-aided design (CAD) drawings, three-dimensional (3D) perspective of site, high resolution ground photography, and a $360^{\circ}$ photography viewer.

\subsection{Statement of the Problem}

The problem at hand was that Montclair first responders needed a better system to respond to a crisis at the local high school. They needed a system that could provide necessary critical information and be implemented in mission planning and response to emergencies. They needed an easy to use customized application that could provide this necessary information with a few clicks of a computer mouse. For example, if an emergency situation occurred in classroom $x$, it would be vital for the responders to have easy computer access to location information and visual perspective about classroom $\mathrm{x}$. It was imperative that this application support personnel during execution of an emergency response with minimal loss of life or property. It is also critical that local law enforcement, firefighters, and emergency personnel be informed of the most up-to-date information in an understandable and easily accessible format.

\subsection{Project Overview}

Steven Dague, GIS Specialist for the City of Montclair, and the Montclair police and fire departments required an enhanced application utilizing GIS that would better prepare their personnel to respond to situations at the Montclair High School. At the request of the client, the project was designed as a customized user interface created primarily with Environmental Systems Research Institute Inc. (ESRI ${ }^{\mathrm{TM}}$ )-produced ArcGIS ${ }^{\mathrm{TM}}$ software that could be loaded onto laptops and other computers for use in the field or planning rooms to provide both two-dimensional (2D) and three-dimensional (3D) visualizations. In an effort to design a robust application to support the emergency personnel, it was important to make sure every feature of the high school inside its borders was referenced. This included buildings, classrooms, offices, parking areas, athletic fields, and tennis courts. The outlying areas and significant structures surrounding the school were identified in the project as well, but not as thoroughly detailed. Graphic visualizations included maps, a 3D visualization, aerial photography, CAD drawings, and digital 
photography. Most of these visualizations were accessible by turning on layers in the table of contents, or by clicking on hyperlinks. These graphic representations help responders understand the full scope of the event in order to provide the ability to quickly pinpoint areas within the school that need a timely response. The client required that the application be designed for use by personnel without knowledge of basic functions of a GIS-based tool.

\subsection{Project Site Overview}

Montclair High School consists of a large campus situated on a .25 mile by .25 mile parcel in a residential area of Montclair. Figure 1 presents a map representation of the school's main facilities, which are primarily single-story and comprised of a mix of exposed corridors and interior hallways. With a population of approximately 3300 students, the main facility consists of 117 classrooms, 40+ offices, and 34 portables buildings, with numerous other rooms and facilities. The tallest structure on campus is the north gymnasium, approximately 40 to 50 feet (12 - 15 meters) in height. There are numerous points of entry for students and faculty located on all sides of the buildings; however observations show that students primarily access the main portions of the high school through the front entrance on Benito Street and the two southern entrances near staff parking and the south gymnasium. The remainder of the school grounds consists of large athletic fields to the south and west, and a large parking lot to the northwest that is used by both students and faculty.

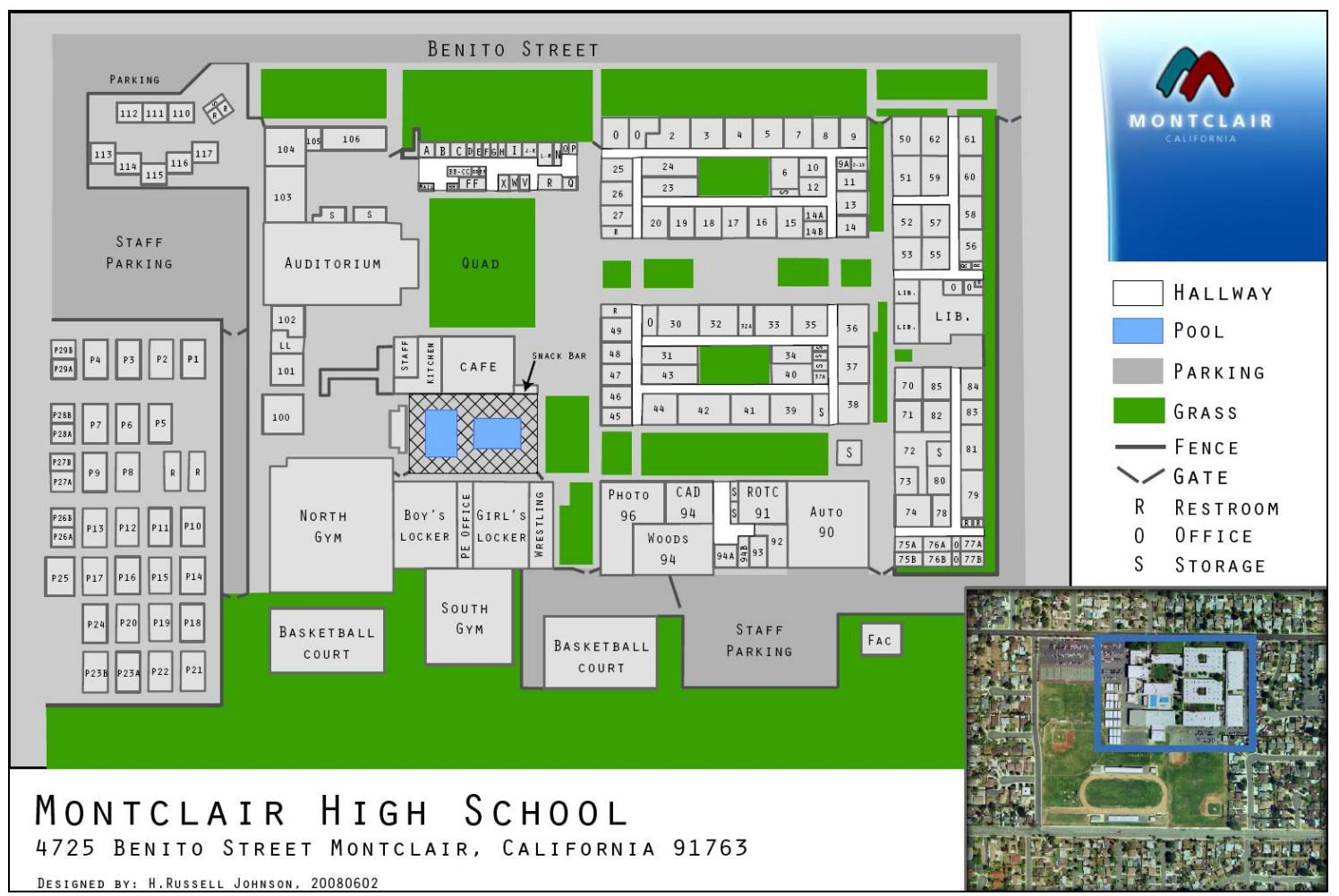

Figure 1. Reproduced map of Montclair High School, Montclair, CA 


\subsection{Goals and Objectives}

The goal of this project was to design an application that would support the critical mission of emergency personnel in the event of contingency at Montclair High School. This application will be designed so that it serves as a emergency response model for future applications at other sites located throughout their jurisdiction such as Montclair City Hall, middle and elementary schools, and any other locations deemed potential targets of opportunity. Furthermore, this GIS model can be translated to schools throughout the United States.

\subsection{Project Workplan}

This project was completed using six planned major tasks, which ranged from an initial requirements meeting and planning with the client, to the MIP Defense and Acceptance. Throughout the duration of the project there was direct contact with the client at least once a month to ensure that project development was moving along smoothly and to address any concerns. A workflow diagram displays the necessary tasks from start to completion (Figure 2). Each task is addressed in this report in the order they were completed.

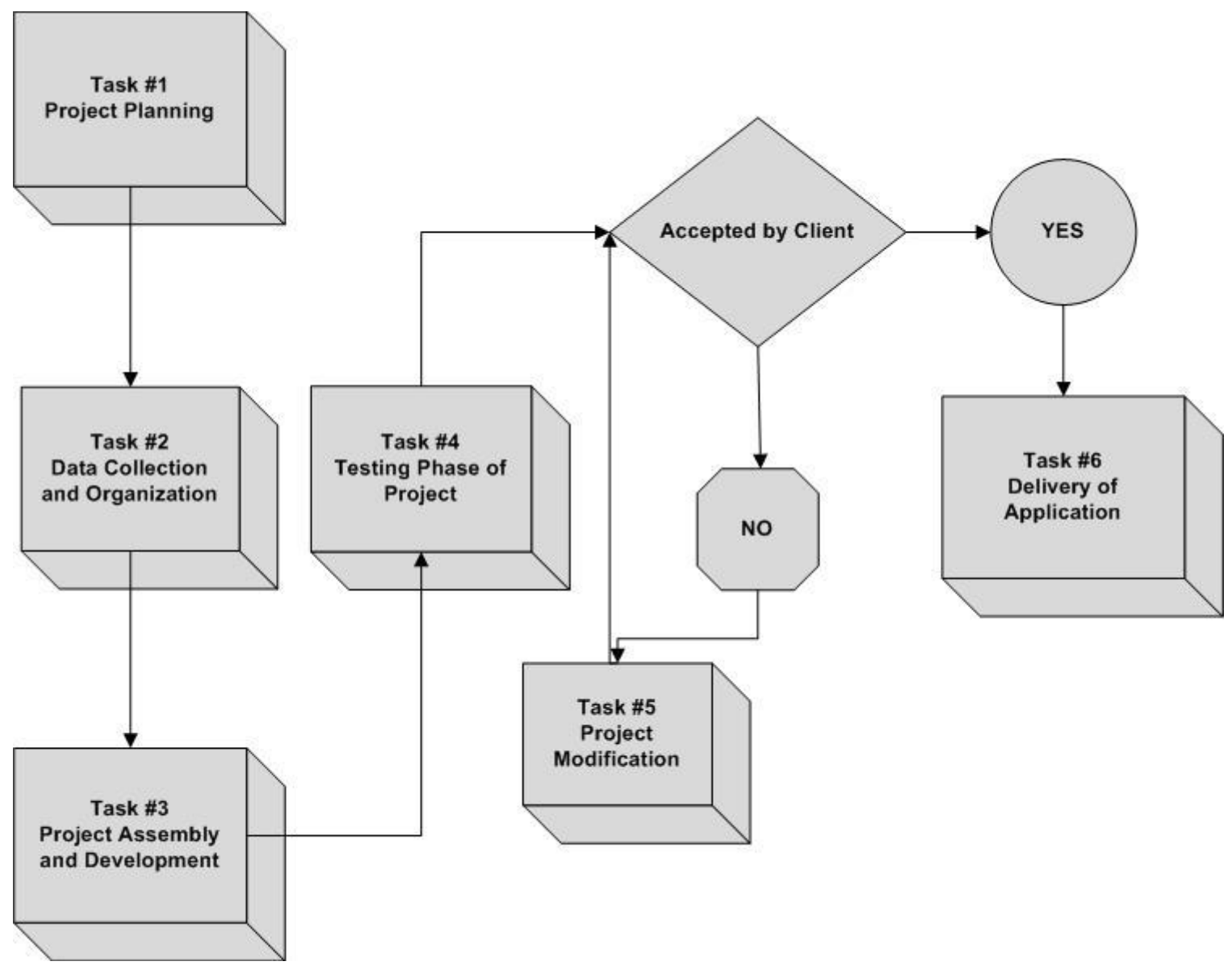

Figure 2. Project workflow diagram A 


\section{Similar Work and Review of Literature}

\subsection{Similar Work}

Prepared Response, Inc, a privately held Seattle, Washington-based company, has created a customized emergency response product to support the critical information needs of

first responders. Rapid Responder ${ }^{\circledR}$ provides emergency management personnel such as fire and police responders with a computer-based array of tools including: imagery and photography, access routes, detailed floor plans, utility access points, response pre-plans, and assembly areas, all of which is essential for a well planned emergency response. Rapid Responder ${ }^{\circledR}$ is currently accessible in 460 high schools and over 1200 middle schools and elementary schools in the state of Washington (Prepared Response Inc., 2008).

The Rapid Responder® has been successfully deployed in real life scenarios, such as the school shooting incident at the Lewis and Clark High School in Spokane, Washington, on September 22, 2003. In this incident a student gunman discharged a weapon and locked himself in a science classroom. After contacting emergency personnel, school safety officials quickly deployed the Rapid Responder ${ }^{\circledR}$ in order to access critical information about the classroom. After establishing a makeshift command center inside the school, the information from the Rapid Responder ${ }^{\circledR}$ was easily passed on to first responders at the scene. This application is accessible by a number of sources, such as internet, network, or portable storage device. The emergency personnel can view the floor plan for the classroom, identify utility shutoff locations, and gain valuable knowledge of surrounding rooms to enhance an assault on the gunman (Finnell, 2006). " "In 12 minutes we responded, contained the shooter, and evacuated the school. I was in the command post and I couldn't believe it,' said Roger Bragdon, Spokane Chief of Police. 'Every question we had and every contingency we had to plan for was answered by the Rapid Responder system" " (Finnell, 2006, p.49). In this scenario, and others in which emergency responders are presented with a daunting task, time was a critical factor. This application saved time by easily providing the critical information and directing the attention of the responders to resolving the crisis (Finnell, 2006).

\subsection{Review of Literature}

Many life-altering events can occur in the critical minutes just after a terrorist attack, hostage crisis, natural disaster or other emergency. It is therefore imperative that first responders have a coordinated plan in place in the event of an emergency. Preparation minimizes the number of casualties and the magnitude of injuries following an emergency. The 1999 Columbine High School shooting is a prime example of how failures in the preparedness of first responders led to tragedy that might have been avoided. After the massacre, there was intense criticism from the media and public of the emergency personnel response. There were questions regarding the Special Weapons and Tactics (SWAT) unit's lack of timeliness, as well as the lack of communication between local law enforcement and faculty and students trapped inside the school (Reed, 2007). All in all, the response by Jefferson County emergency personnel to Columbine High 
School was a disaster in itself, largely stemming from the difficult task of acquiring basic, yet critical information about the school's layout (Reed, 2007).

Geographic information systems (GIS) are now at the forefront in the development of emergency management response plans and have enhanced preparedness of first responders. The difficulty of gathering basic data on the high school was among many mistakes that led Jefferson County law enforcement and crisis personnel to address important problems that occurred with the event, and then meet with the county's GIS team to generate a readily available emergency response database (Reed, 2007).

By contrast, GIS was an integral part of the rescue and relief effort following the terrorist

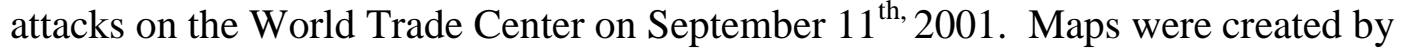
newspapers and other publications using GIS to communicate information to both the public and to emergency response personnel. Furthermore, the use of GIS generated maps was vital during damage assessment. This event revealed the true importance of GIS in emergency management (Bruzewicz, 2003; Cahan and Ball, 2002; Cutter, 2003; Thomas, Cutter, Hodgson, Gutekunst, and Jones, 2002). New York City was ahead of the curve; the GIS system was in place prior to the occurrence of emergency event.

The value of a GIS emergency response system is only as valuable as the GIS knowledge of the user, or in this case the first responder. Many first responders are not educated in or aware of GIS (Cutter, 2003; Galloway, 2003). This demonstrates the importance of knowing the user to create a system that can be utilized by the least knowledgeable first responder, but to generate production that is understandable on all levels of personnel (Cutter, 2003; Galloway, 2003). GIS knowledge of first responders can be enhanced by creating systems that promote the technology in an understandable format and further their desire to learn the new geospatial technology (Cutter, 2003; Galloway, 2003). For example, in addition to a database of building information, the new response system for Jefferson County included digital maps of the school's layout or floor plan. This system included building photos, satellite aerial photos, utility shutoffs, emergency contact numbers, evacuation routes, and among other data available to the emergency personnel (Reed, 2007).

The examples of GIS and its utilization following the September $11^{\text {th }}$ attacks prompted researchers to expand the capabilities of GIS and emergency response. There has been increased focus on software development and programs that represent various environments in 3D perspective from a 2D perspective. "After 9/11, interest in threedimensional models (representing buildings or underground systems) for emergency response rapidly increased" (Lee, 2006, p.513). A 3D system can allow the user to visualize the external and internal structures of a building, such as the floor plans of rooms using computer-aided design (CAD) representations (Lee, 2006). It can also present the user with a $3 \mathrm{D}$ view of the physical environment, such as terrain, within an area that may have been affected by natural disaster and help emergency personnel with disaster planning. GIS has played an integral role in emergency response, and incorporating the 3D perspective into a system designed to respond or plan for a catastrophic event will only enhance response to the situation. 
GIS played an integral role in the aftermath of Hurricane Katrina in New Orleans in September of 2005. GIS specialists utilizing a variety of data aided search and rescue efforts of stranded residents. For example, residential addresses were integrated with overhead imagery to assist rescue teams in locating stranded residents who had called in for assistance. Flood data overlaid with map data was also important to identify areas that were more flood prone to assist in navigating streets of New Orleans. Although GIS was considered a success in response to the catastrophe, it could have been more useful had the use of time been more efficient in planning prior to landfall of the storm (Curtis, Mills, Blackburn, and Pine, 2006).

Columbine High School, September $11^{\text {th }}$, and Hurricane Katrina were all significant events in U.S. history. While these tragedies may not have been avoidable, the response of emergency personnel in both events was critical. Columbine demonstrated how the lack of preparedness can lead to unnecessary casualties and more severe injuries, whereas 9/11 and Hurricane Katrina demonstrated how GIS tools can facilitate response in the aftermath of an emergency. In conclusion, the successful use of GIS can minimize the impact of a terrorist attack, hostage crisis, natural disaster or other emergency events by providing a high level of preplanned coordinated response and communication between emergency personnel and school officials during the event. 



\section{Methods, Feasibility Analysis, Requirements, and Design}

\subsection{Project Workflow}

As introduced in Chapter 1, this project was completed through a series of six planned major tasks that ranged from the project planning to the delivery of the application to the client. The workflow diagram in Figure 3 shows all the major tasks as planned throughout the duration of this project.

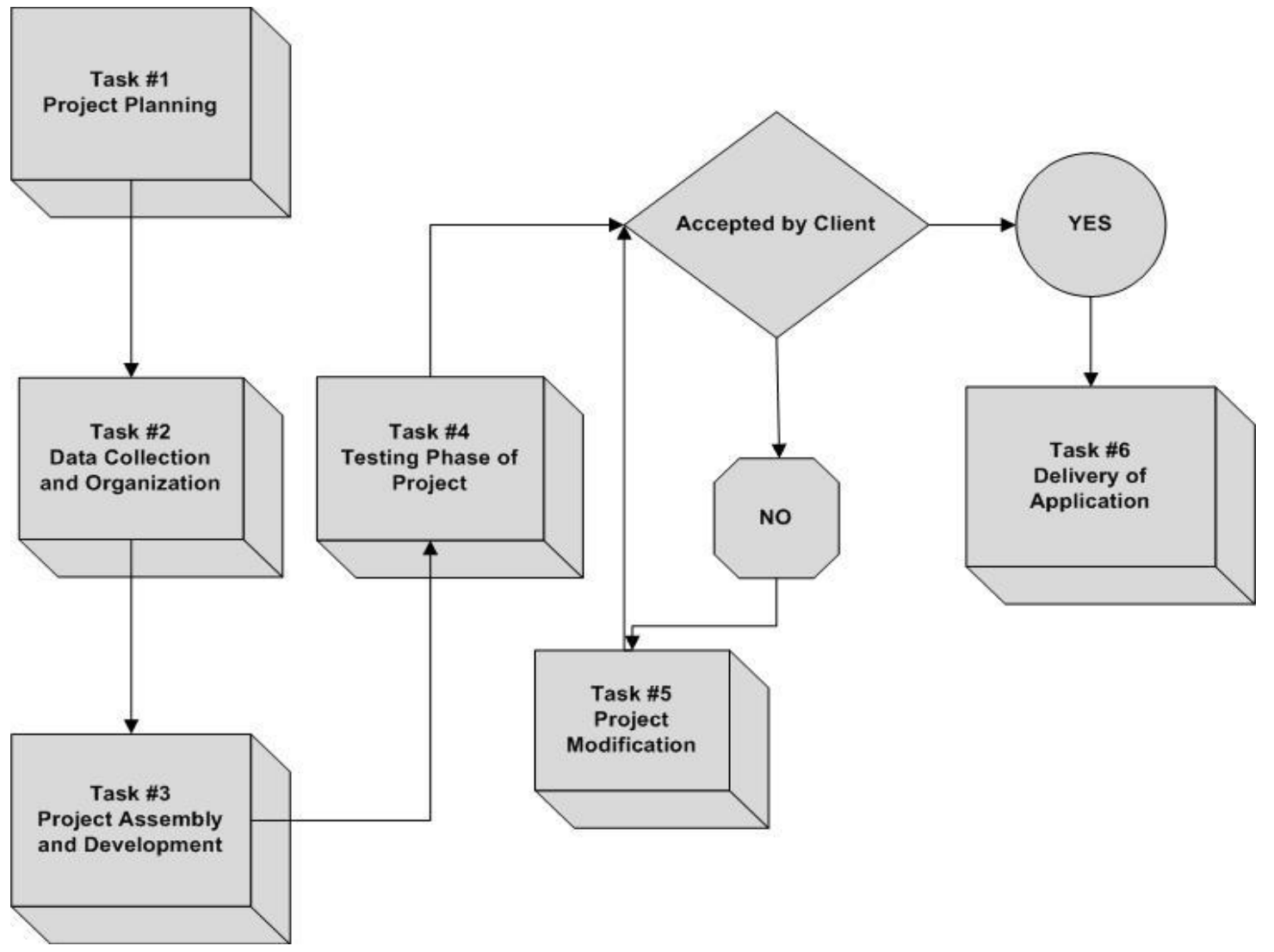

Figure 3. Project workflow diagram B

\subsection{Schedule}

Completion of this project, within the required twelve-month timeframe, depended on a structured and well organized schedule. Appendix B shows the schedule for this project. There are nine major tasks identified on the table. Beginning with the Project

Requirements and Planning Meeting with the client that began on January 23, 2008, each task was assigned an appropriate start date and finish date. 


\subsection{Time Budget}

The budget for this project was based upon the estimated number of hours that were spent completing each major task associated with the project workflow and schedule. This is shown below in Table 2.

Table 1. Time Budget

\begin{tabular}{|lll|}
\hline Task & Description & Hours \\
\hline 1 & Requirements and Planning Meeting with Client & 30 \\
\hline 2 & Data Collection and Organization & 200 \\
\hline 3 & Project Assembly & 250 \\
\hline 4 & Testing Phase of Project & 10 \\
\hline 5 & Project Modification & 40 \\
\hline 6 & Delivery and Training & 8 \\
\hline 7 & MIP Defense and Acceptance & 341 \\
\hline
\end{tabular}

\subsection{Business Need}

The increase in threats and incidents in American school systems are stark reminders of the importance of being prepared to react to potentially tragic occurrences. It also furthered the need for a better system to respond to these incidents and a tool to prepare for a potential problem before it actually occurs. This project provides the City of Montclair with a system to support better planning and response to a crisis at Montclair High School. Following multiple interviews with the client and experienced emergency response professionals, the importance of having an application that could provide 
emergency responders with the critical information to respond to a contingent event became apparent.

In an effort to best explain how this product can be deployed and used in a real situation, the following hypothetical scenario provides a good example:

A hostage situation has occurred at the Montclair High School. Full of students and a teacher, classroom \# 51, inside Building $\mathrm{N}$ on the east side of campus, has been overrun by armed hostage takers. First responders have just arrived at the school. Streams of questions have come from the police special unit commander:

- Where is Classroom 51? Building N?

- What are the routes to access Classroom 51?

- What does the interior of Classroom 51 look like?

- How many points of entry are there to Classroom 51?

- What interior components exist such as ventilation and lighting?

- What construction materials is Classroom 51 made with? (i.e. brick or concrete wall structure)

This GIS application provides answers to those questions. Without accessibility to this actionable intelligence, it would be very difficult for responders to react appropriately.

\subsection{Feasibility Analysis}

The following feasibility analysis first addresses the technical factors that played integral roles in the technological development of the application. Followed by important economic factors that directly contributed to the successful completion of the application in a timely fashion. Finally, the feasibility analysis addresses the client role factors that proved to be vital with the support and expertise to enhance the completion of this project.

\subsubsection{Technical}

This project primarily required the utilization of ESRITM ArcGIS software with an ArcInfo license. Application production also required Google ${ }^{\mathrm{TM}}$ SketchUp for creating $3 \mathrm{D}$ visualizations, and Google ${ }^{\mathrm{TM}}$ Earth to view the $3 \mathrm{D}$ visualization. The completed application was designed to be installed or uploaded onto either a laptop or desktop computer that has an ArcInfo-level ArcGIS license and the Google ${ }^{\mathrm{TM}}$ Earth application.

\subsubsection{Economic}

There were a number of economic factors that could have hindered successful completion of this application. Time management was one of the most crucial issues affecting the success of this project. It was extremely important to establish and adhere to a strict schedule to ensure timely completion. Data collection was also an important determinant of project completion. If the required data was inaccessible, the project would have suffered greatly. It was imperative that every step be taken to collect the necessary 
information. The benefits of this project are improved efficiency and response to an emergency crisis at the Montclair High School and subsequent protection of life and property.

\subsubsection{Client Role}

The client, Mr. Steven Dague, played a vital role in coordinating meetings with outside contacts, including representatives from the Montclair fire and police departments, and Montclair High School officials. He was integral in scheduling meetings and assisting in the collection of the necessary data to complete the application. The client provided access to a variety of data sources that included aerial photography of the study area. In addition to the data, the client provided access to equipment such as a Trimble GeoXH handheld Global Positioning System (GPS) unit and a Ricoh GPS-ready digital camera. Both devices worked in a seamless fashion to gather field data.

\subsection{Risk Assessment}

When undertaking a large project, there are always the potential for risks that could hinder successful, on-time completion. There were three critical risks during this project that, if not properly mitigated, may have prevented the completion. The three risks are indentified in Table 3 below, and were ranked at the beginning of the project. The table identifies the risk, followed by a number rating between 1 and $5(1=$ least severe and $5=$ most severe) to determine the risk level, mitigation plan for each risk, and an exposure rating. Each risk was mitigated to reduce or eliminate any potential problems during the project.

Table 2. Risk Assessment

\begin{tabular}{|c|c|c|c|c|}
\hline Risk & Severity & Probability & Mitigation & Exposure \\
\hline $\begin{array}{l}\text { Inexperience } \\
\text { with Software }\end{array}$ & 3 & 3 & $\begin{array}{l}\text { - Plan to take all opportunities for } \\
\text { online or instructor-led courses at } \\
\text { ESRI } \\
\text { knowledge of the software. }\end{array}$ & 9 \\
\hline $\begin{array}{l}\text { Time } \\
\text { Management }\end{array}$ & 5 & 3 & $\begin{array}{l}\text { - Create a strict schedule to } \\
\text { complete tasks required to finish } \\
\text { project, and abide by the strict } \\
\text { schedule. } \\
\text { Maintain constant communication } \\
\text { with client to make sure tasks are } \\
\text { being completed on a schedule. }\end{array}$ & 15 \\
\hline Data Acquisition & 5 & 2 & $\begin{array}{l}\text { - Identify areas of data collection } \\
\text { and work hard to acquire the } \\
\text { necessary data. } \\
\text { - If data is absent, then adjust } \\
\text { accordingly to stay on schedule } \\
\text { for completion. }\end{array}$ & 10 \\
\hline
\end{tabular}




\subsection{System Requirements}

During the planning and requirements phase, the client addressed a number of requirements for the application, functional and non-functional, the majority of which were considered mandatory by the client. Table 4 identifies the Functional Requirements for the system, and Table 5 highlights the Non-Functional Requirements.

Table 3. System Functional Requirements

\section{Identifier}

3.1 Overall The system shall provide user with necessary information to Mandatory System view the Montclair High School in two dimensional and three dimensional visual environments.

$\begin{array}{lll}\text { 3.2 Data } & \text { The system shall store all pertinent data for each facility or } & \text { Mandatory } \\ \text { Storage } & \text { information layer in a file geodatabase. }\end{array}$

\subsection{Data} The system shall allow the user to turn on/off the air photo, Access $3 \mathrm{D}$ view, school map, $\mathrm{CAD}$ drawing, and ground photo Logic layers with the click of a mouse.

3.4 Display

The system shall display locations of classrooms, offices, storage rooms, restrooms, library, auditorium, athletic facilities, athletic fields, etc. in different layers and in different visual environments (2-D, 3-D, $360^{\circ}$ photos).

\subsection{Tools}

The system shall provide a customized toolbar with the necessary tools to allow users to navigate the application by selecting features, zoom in/out, pan across, fly through, jump to the full extent, and hyperlink to photos. 
Table 4. System Non-Functional Requirements

\begin{tabular}{|lll|}
\hline \multicolumn{1}{|c|}{ Identifier } & \multicolumn{1}{c|}{ Requirement } & Priority \\
\hline 4.1 Accessibility & $\begin{array}{l}\text { The system shall be accessible by field } \\
\text { computer during operations at the school. }\end{array}$ & Mandatory \\
\hline 4.2 Security & $\begin{array}{l}\text { The system should allow only system } \\
\text { administrators access to manipulate or } \\
\text { update information. }\end{array}$ & Desirable \\
& $\begin{array}{l}\text { The system shall be stored on City of } \\
\text { Montclair or Montclair Police Department } \\
\text { computers for security purposes. }\end{array}$ & Mandatory \\
\hline 4.3 Usability & $\begin{array}{l}\text { The system shall be designed at a level of } \\
\text { complexity or understanding by non-GIS } \\
\text { professionals. }\end{array}$ & Mandatory \\
\hline 4.4 Documentation & $\begin{array}{l}\text { The system shall have detailed } \\
\text { documentation or Standard Operating } \\
\text { Procedures (SOP) on how the system was } \\
\text { created and how it operates. }\end{array}$ & \\
\hline
\end{tabular}

\subsection{System Architecture}

The system architecture for this application can be broken into three main components as shown in Figure 4. First, the Data Input consists of all the data compiled in the project application. It is made up of the data collected from the field, such as detailed ground photography and global positioning system (GPS) data. It also consists of hardcopy maps and parcel data acquired from the client. Computer-aided design (CAD) drawings for each classroom or building were also included, as well as aerial photography of Montclair High School.

This data was further processed using ESRI ${ }^{\mathrm{TM}}$ ArcGIS $^{\mathrm{TM}}$, Google ${ }^{\mathrm{TM}}$ SketchUp, and Google ${ }^{\mathrm{TM}}$ Earth programs to create a customized application that draws critical information through a number of information layers. All of the information in this application was stored in a file geodatabase. 
Following the production and development, the application was designed to be deployed into the field as a customized GIS field application used by emergency responders in a situation at the Montclair High School. The final product was designed to be used remotely on a field computer, without a server connection.

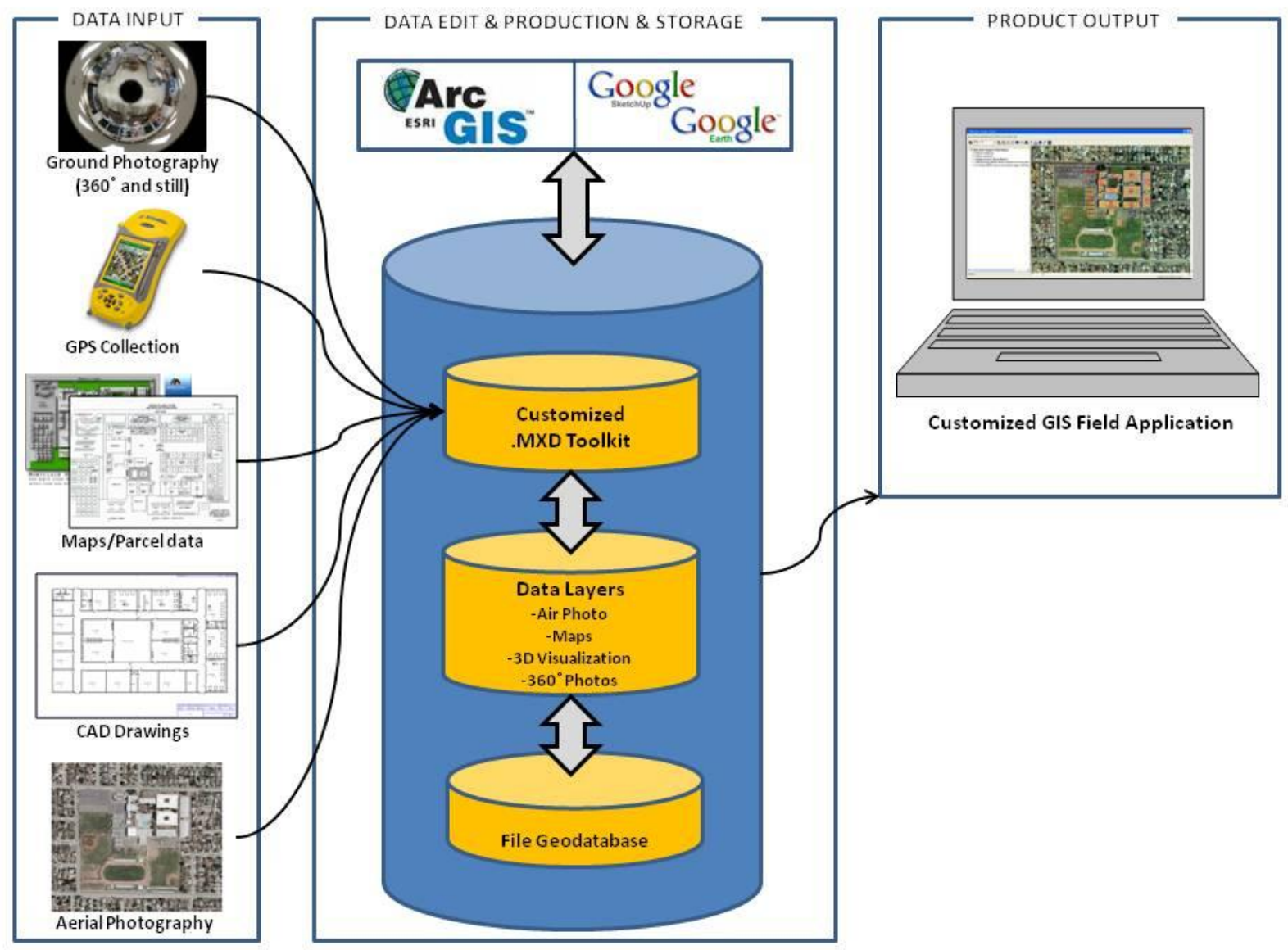

Figure 4. System Architecture 



\section{Data Development}

The data needed for this application were identified with the client and other Montclair emergency response personnel during the planning and meeting phase of this project. This phase of development included a number of steps such as the collection of new field data, the compilation of collected data and already existing data, and the development of the database that would be used in the project application.

\subsection{Data Sources}

The data that were used throughout the development of this emergency response application were obtained through a number of sources. First, the client was able to provide aerial photography of Montclair High School and the surrounding environment (Figure 5). This proved to be invaluable during preplanning and also during application development. The air photo also saves as a layer within the application that gives the user a bird's-eye perspective of the school campus. The aerial photo, which has a Ground Sampling Distance (GSD) of 3 inches, was collected on 22 April 2002 by Landata Systems, Inc. (currently Stewart Geo Technologies) ${ }^{1}$. The aerial photo was provided in a MrSID file format and is 522 megabytes.

\footnotetext{
${ }^{1}$ Stewart Geo Technologies, 5730 Northwest Parkway, San Antonio, TX 78249-3303
} 


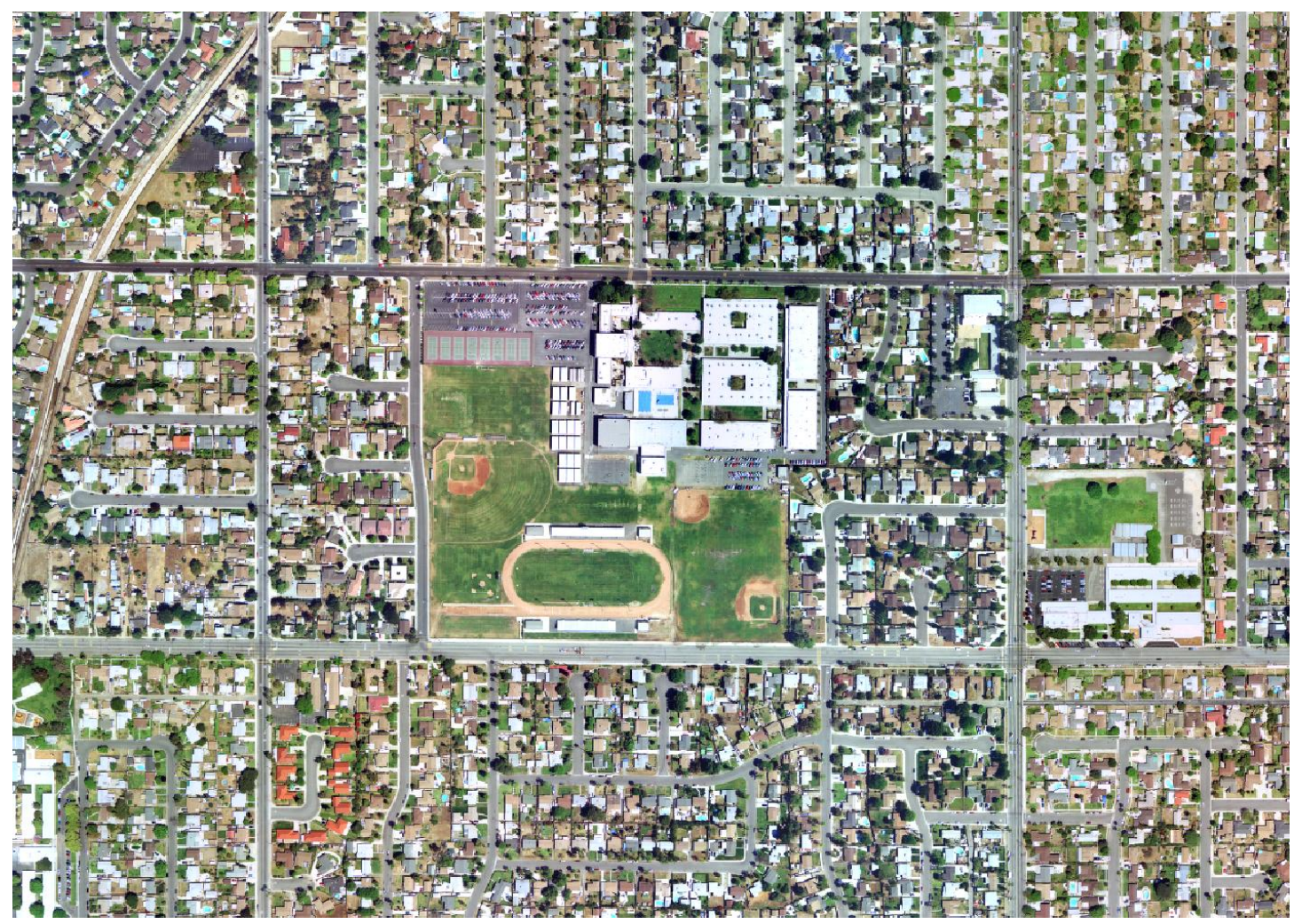

Figure 5. Aerial Photography of Montclair High School and surrounding environment

The client provided a shapefile containing parcel data for the neighborhood surrounding the high school campus (Figure 6). There is no specific attribute information for each parcel, aside from the size of the parcel. It was used to give the user a cartographic understanding or visualization of the density and locations of the residences nearby. This was the extent of the data provided directly by the client. 


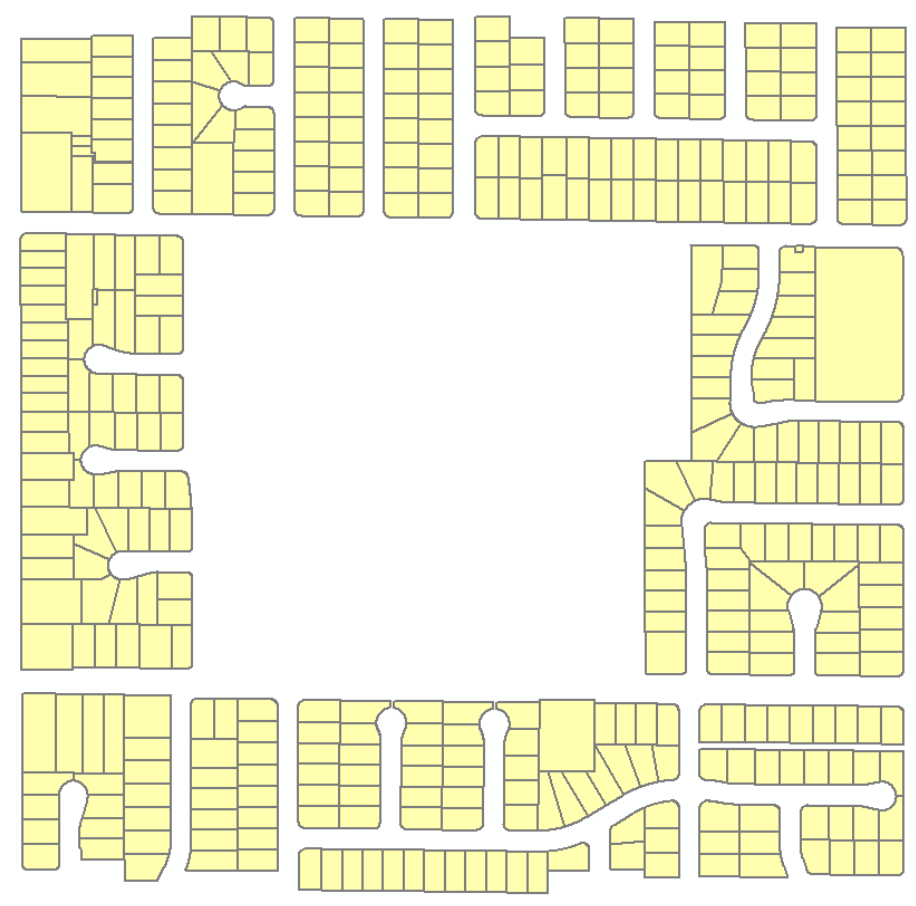

Figure 6. Parcel data shapefile for neighborhood surrounding campus

The following two data sets were acquired through meetings and interviews with Montclair High School officials. The first was obtained through the school Vice Principal and building manager, Mr. Larry Tisdale. Mr. Tisdale provided a copy of the most up-to-date school reference map that identified the locations and names or numbers of all the facilities on campus (Figure 7). This information was extremely important during development of the application because it acted as the main reference source for labeling or referencing all facility locations within the campus. 


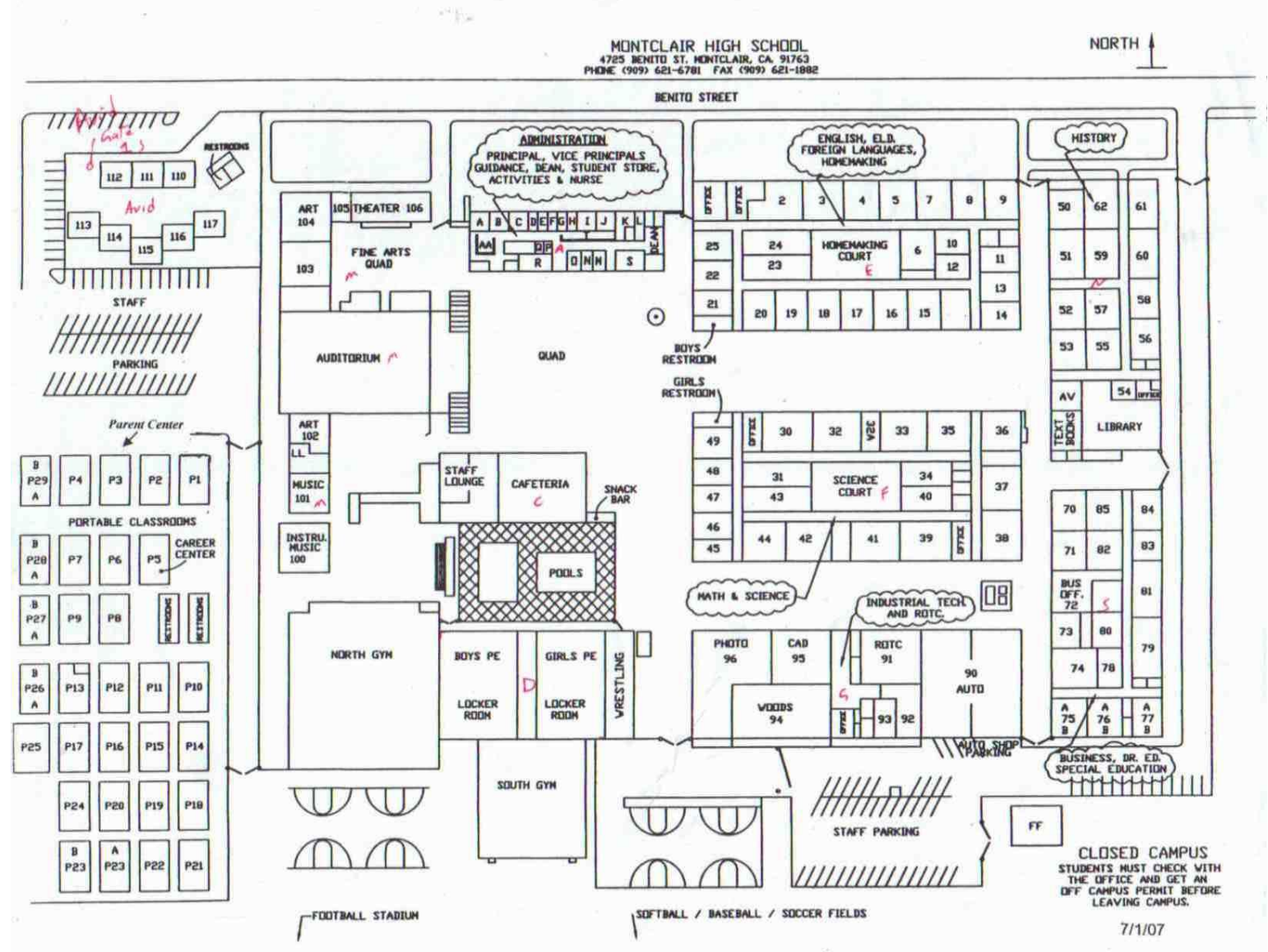

Figure 7. Reference map of the Montclair High School

The second source of data, computer-aided design (CAD) drawings, were acquired through meetings with the school CAD instructor, Mr. Corey Knowlton (Figure 8). The CAD drawings were designed and approved in April 2003. Unfortunately, the names and numbers of the rooms and facilities in each drawing have changed; however, they provided invaluable information with regards to the structural layout of each facility, such as door placement and interior wall locations. This information is extremely valuable to first responders. All CAD drawings are provided as an individual layer in the application. 


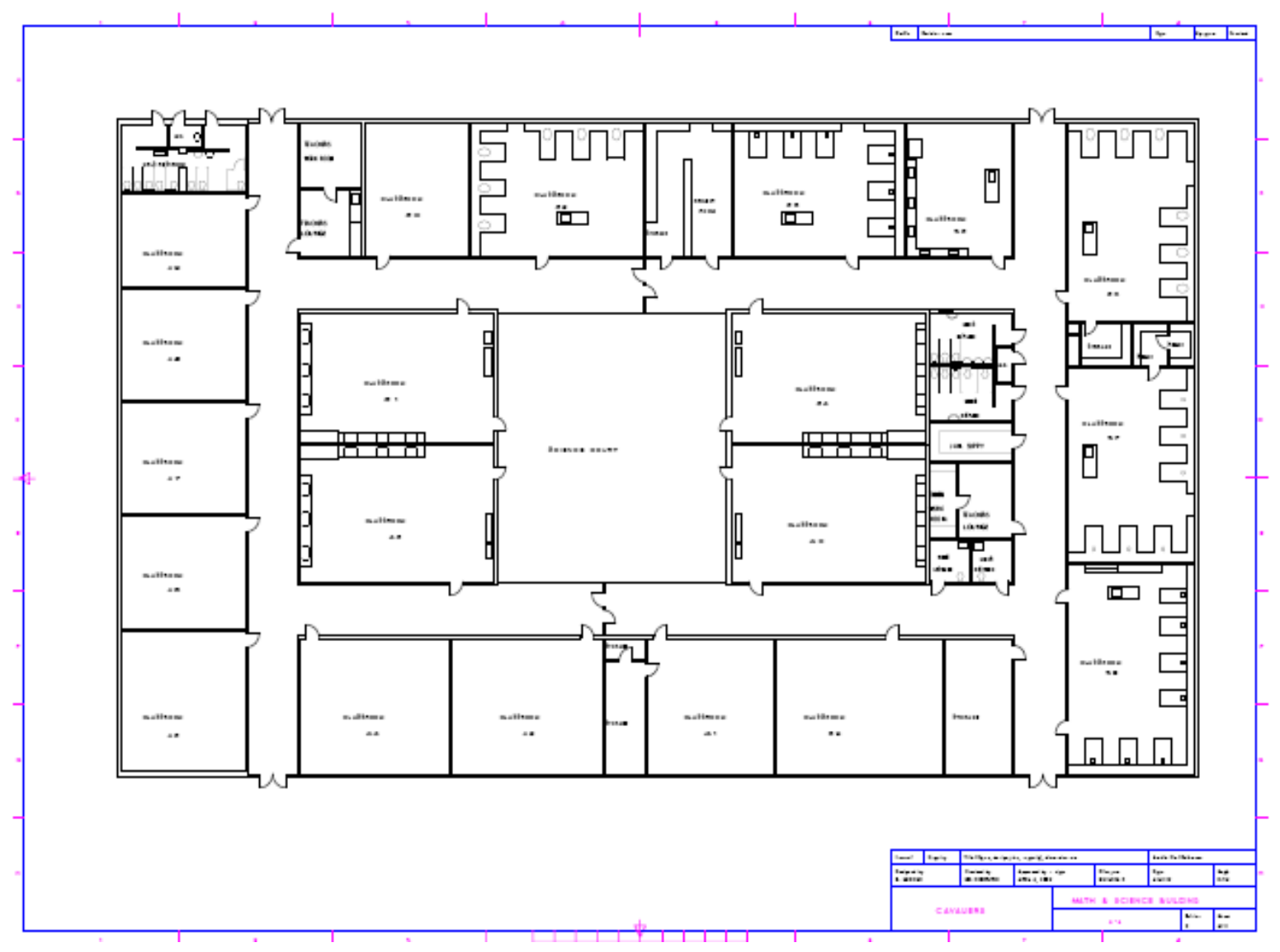

Figure 8. Example of CAD drawing used in application

The final sources of data were ground-based photographs and associated GPS points obtained during field collection at the high school. This information served as an integral part of the entire application. Two types of photographs were taken and applied to the project: conventional still photographs of specific locations, and $360^{\circ}$ photographs taken with a specialized camera lens. These two types of ground photos provide information of extreme value to an emergency responder. Detailed information regarding these two sources of information is provided in the following section on field collection.

\subsection{Field Collection}

Following the requirements and planning phase, the project moved into the Data Collection phase. This was an extremely important part of the project. It was an opportunity to understand the kind of environment and conditions in which an emergency responder might be working.

The total field collection covered a span of five days and roughly 19.5 hours on site. The first two days were dedicated to the collection of exterior points of interest (POI). These POIs included perimeter roads, points of entry such as gates or doorways, athletic fields, and parking lots. The points were collected using both the Trimble GeoXH handheld GPS unit, and the Ricoh Geo-Imaging GPS-ready digital camera (Figure 9). Both units could sync with each other through Bluetooth ${ }^{\circledR}$ technology. A directional azimuth was 
also taken for each photograph to indicate the approximate direction the photograph was taken. Each azimuth was acquired using the electronic compass on a Suunto X6hr wristop computer. Each azimuth was recorded on the Trimble GeoXH GPS attached to the recorded point location. Point locations were collected with the Trimble GeoXH as a back up to the geo-located digital photos that were taken using the Ricoh camera.
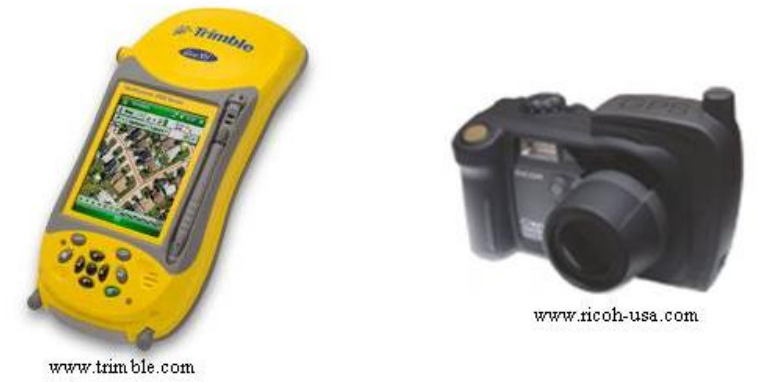

Figure 9. Trimble GeoXH (left) and Ricoh Geo-Imaging digital camera (right)

The third, fourth, and fifth days were dedicated to interior collection at the high school, including classrooms, offices, restrooms, storage, library facilities, auditorium, athletic facilities, and cafeteria facilities. The client, author, and a member of the high school janitorial staff entered each facility equipped with the school reference map, paper and pen, and a camera with a specialized mirrored lens attached (Figure 10). 


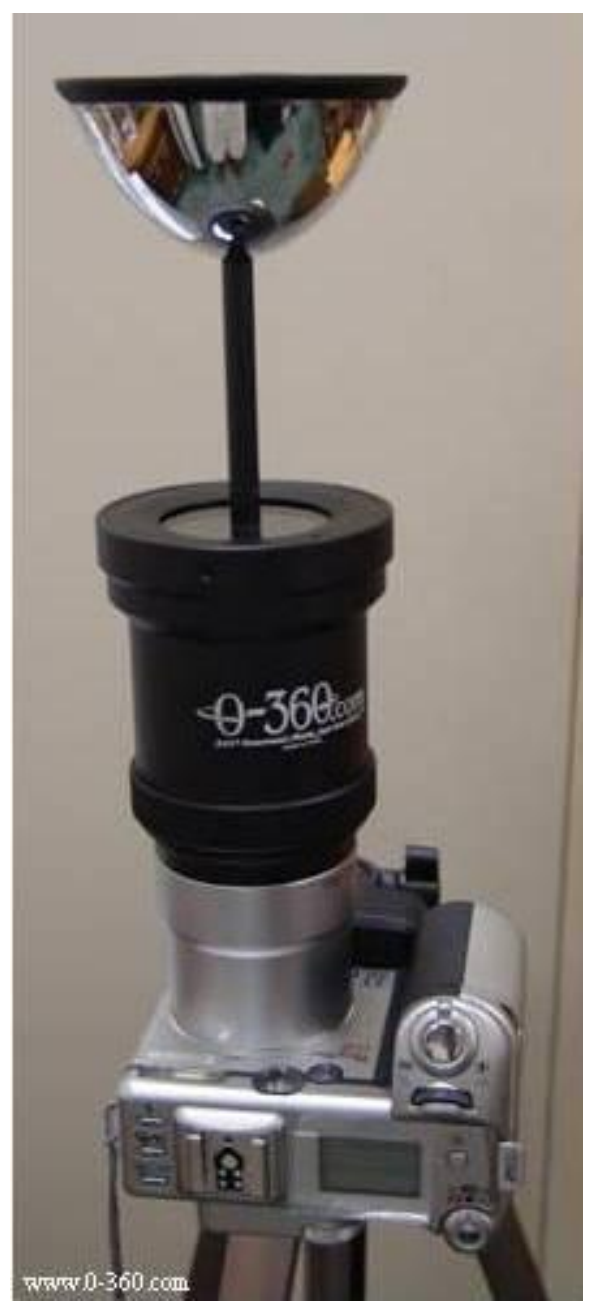

Figure 10. Specialized camera lens used for photo collection

This specialized lens could capture a $360^{\circ}$ photograph of an entire room or facility with one camera exposure. The camera that was used with the $360^{\circ}$ lenses was a Canon Powershot G9 with a resolution of 7.1 megapixels. The company that produced the lenses is called 0-360.com ${ }^{\mathrm{TM}}$, and is a division of Bellissimo, $\mathrm{Inc}^{2}$. Each $360^{\circ}$ photograph in its raw format initially came out with a "fish-eye" appearance. The company also provides a software program called 0-360 Unwrapper ${ }^{\mathrm{TM}}$ that allows the user to unwrap the raw photo. It changed each raw image, compressed 337 high-resolution photos into $265 \mathrm{MB}$, and automatically saved the images on the computer. This unwrapped image is saved as both a .jpg and a .mov file format into a specified folder on the computer. Unfortunately, during the lossy compression method, the images lost some of their quality or resolution. The .mov file can then be opened by using a QuickTime viewer, which allows the image to be viewed in a $360^{\circ}$ fully interactive format. The user can pan around the image as well as zoom in and out. This provided a unique function to the application. The entire $360^{\circ}$ photograph processing is outlined below in Figure 11 .

\footnotetext{
${ }^{2}$ 0-360.com, division of Bellissimo, Inc. 1802 N. Carson St. Suite 110, Carson City, Nevada 89701
} 


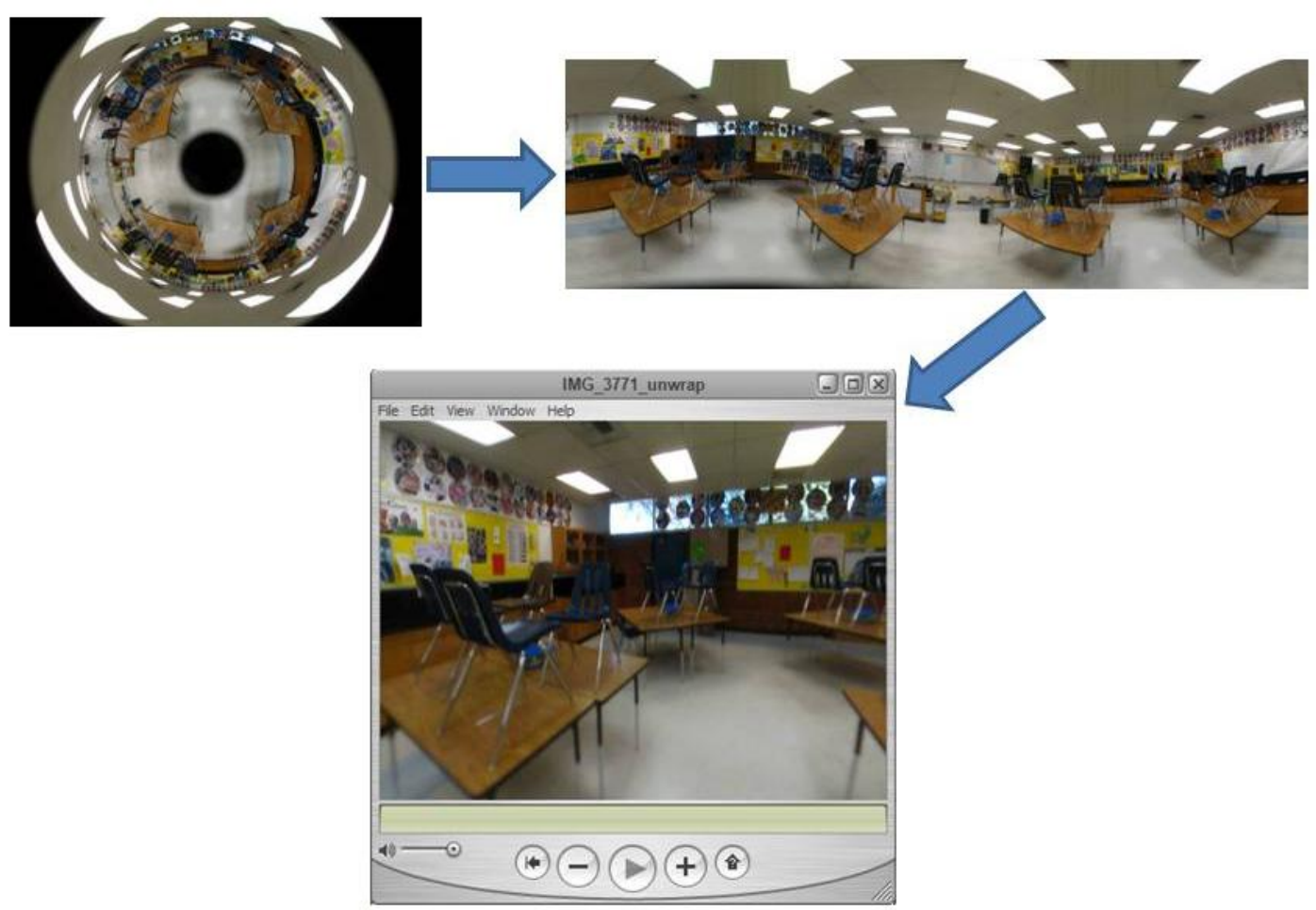

Figure 11. Conversion of $360^{\circ}$ photo (top left) into a QuickTime viewable format

The entire field collection phase produced a total of 550 photographs on 339 point targets around the high school campus, all of which were incorporated into the GIS application. The only real issue that was experienced during the collection phase was time management related. The collection had to be planned around the rental of the camera and lens, which had to be shipped from Nevada. The camera and lens was rented for a total of six days at $\$ 99$ for the first three days and $\$ 15$ for each additional day, so planning had to be precise. The purchase price for the camera lens alone is $\$ 595.00$. The lens is designed to fit on cameras with threaded lens attachments. Coordination between the client and school officials had to coincide with the camera rental. Finally, there had to be a representative from the school present to provide access to the school grounds for collection.

\subsection{Data Assembly}

Following the collection of all data necessary for this application, all information was organized in a concise and understandable format that would meet the requirements of the client and the needs of the user.

All the $360^{\circ}$ photos were converted, compressed, and saved to a usable format for future use in the application development. Each raw .jpg photo was converted using the 0-360 Unwrapper ${ }^{\mathrm{TM}}$ program. This free software download takes the .jpg file and quickly converts it into a panoramic .jpg and a .mov file, allowing the user to convert the photos in large batches instead of individually. Each .mov file could then be automatically opened in a QuickTime viewer to create a $360^{\circ}$ visualization of the environment. All the 
.mov files were consolidated and saved into a separate folder on the $\mathrm{C}$ drive to reference during application development. The remaining .jpg files for the $360^{\circ}$ photos could be discarded. All the non- $360^{\circ}$ digital ground photographs remained as .jpg files and were consolidated in the same folder on the $\mathrm{C}$ drive for future application use. Each digital ground photograph $\left(360^{\circ}\right.$ and non- $360^{\circ}$ ) was created as a point shapefile in ArcGISTM that referenced where the photo was taken. This will be further discussed in a later chapter.

The aerial photography that was obtained from the client was first clipped to a roughly one to two blocks, or 500 to 1,000 foot, radius around the Montclair High School. This was accomplished using the mask tool in ArcMap. It was later determined that the specified one-to-two block, or 500 to 1,000 foot, radius around the school would not be sufficient enough. The client requested that the extent of the aerial photo go beyond this specified area in the event that the area of operation or crisis extends beyond the specified boundaries. To rectify this, the entire unmasked air photo was kept in the application, but to be discussed later it is a layer option that can be activated after the initial application startup.

CAD drawings acquired from Mr. Knowlton were in native .dwg format. To be used in the application, each drawing had to be imported into ArcGISTM software and converted into a feature class.

To maintain accuracy, all data were stored in the same spatial reference system, NAD 1983 State Plane California Zone V FIPS 0405. All data that were not originally spatial referenced, including the CAD drawings and the digital ground-based photos, were referenced to this projection during conversion into feature classes.

\subsection{Database Development}

All the necessary data for the application was organized and contained using an ArcGIS ${ }^{\text {TM }}$ file geodatabase that was created in ArcCatalog. This ArcGIS ${ }^{\text {TM }}$ file geodatabase was chosen instead of the ArcGISTM personal geodatabase because of potential size restrictions to the personal geodatabase. The personal geodatabase has a maximum size limit of 2 gigabytes, while the file geodatabase can support more than 1 terabyte of data. The potential for the client to update or add more data to the application in the future furthered the need for a database with a much larger maximum capacity. The resulting geodatabase was titled Montclair High School GIS Toolkit. Two feature datasets and three tables made up the database as shown below in Figure 12.

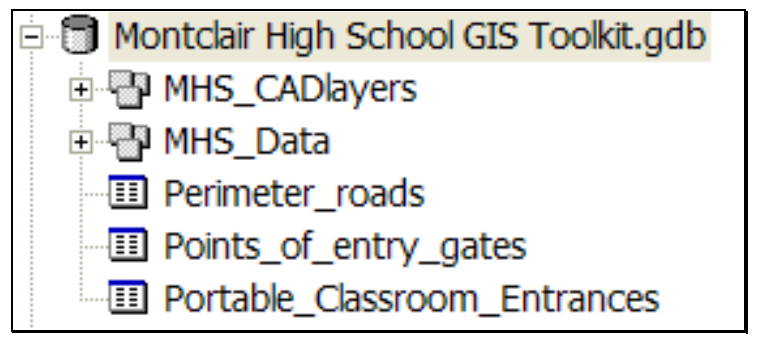

Figure 12. Montclair High School GIS toolkit file geodatabase 
The CAD drawings were organized in a separate feature dataset titled MHS_CADlayers. In this dataset, each building drawing was an individual line feature class. The bulk of the file geodatabase was the MHS_data feature dataset (Figure 13). This dataset contained 46 individual feature classes, ranging from points, lines, and polygons to annotation feature classes. Every layer of information in the application, except for the $\mathrm{CAD}$ drawings and the aerial photo, were stored inside this feature dataset container.

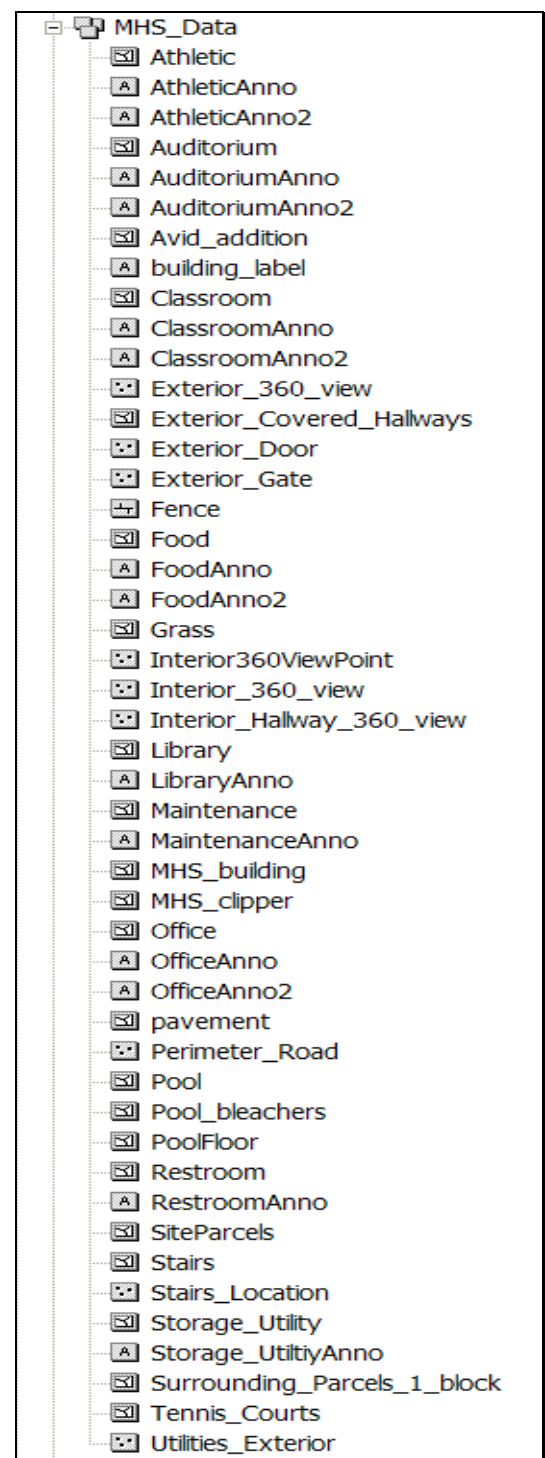

Figure 13. Largest feature dataset in the Montclair High School geodatabase 


\section{Project Development, Testing, and Deployment}

\subsection{Project Assembly and Development}

The next phase of the workflow included assembling and developing the project application. ArcGIS ${ }^{\mathrm{TM}}$ more specifically ArcMap and ArcCatalog were the primary software used to construct and operate the GIS emergency response application. At the client's request, the application was produced using commercial-of-the-shelf software, such as the ArcMap .mxd file format. The majority of the layers for this project were generated using ArcMap.

The first step in the development process was to identify which layers of information were required by the client. After discussions with the client, it was concluded that the most important information should be easily accessible to the user and in a simple format. There were five main layers created for the application as shown in Figure 14.

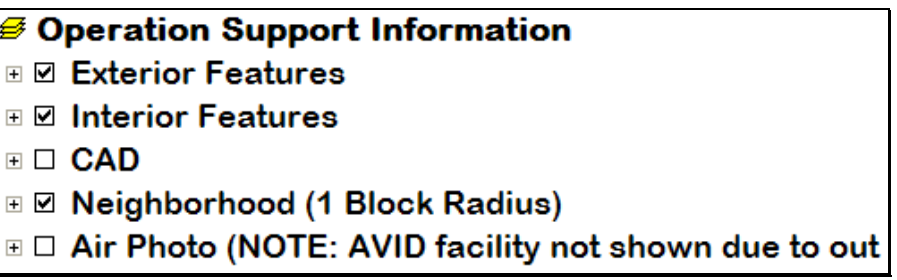

Figure 14. Five main layers of information for application

The Exterior Features layer included exterior POI layers such as perimeter roads, points of entry, $360^{\circ}$ exterior views, and utilities points. The Interior Features layer included interior features such as facilities, hallways, stairways, and $360^{\circ}$ interior views. Finally, individual layers of the CAD drawings, neighborhood parcels, and aerial photography of the area were created.

The second step of development was to create a base map of the Montclair High School. This was accomplished by using the aerial photo and digitizing the school reference map provided by school officials. This was a very time consuming process due to the tedious task of drawing hundreds of polygons of varying sizes. Each polygon digitized represented various features on the map, such as classrooms, offices, pool, grass fields, and parking lots. In addition to polygons, a number of point layers were created to represent locations around the campus that was photographed during field collections. For each point layer, a unique symbol was created to represent the point feature type (Figures 15 and 16). 


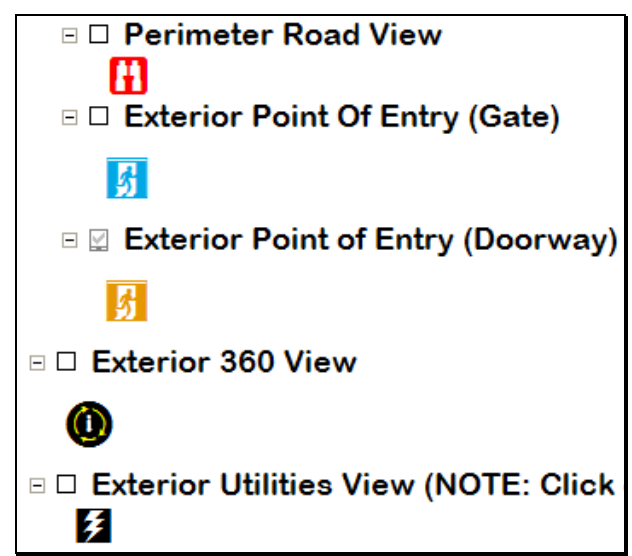

Figure 15. Point symbology for the Exterior Features layer

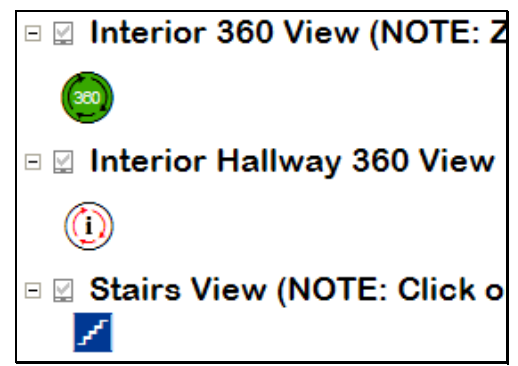

Figure 16. Point symbology for the Interior Features layer

The next step dealt with assigning attribute information to each point or polygon that was digitized for the application. Each point or polygon had attribute values specific to that feature. However, each had similar attribute fields, such as Facility Name, Type, Building Name or Location, and a hyperlink to one or more digital photographs representing the feature. The hyperlink path was directed to a folder located on the computer's $\mathrm{C}$ drive. The attribute for all exterior point features also contained an approximate elevation in feet and a directional azimuth. At time of application deployment, the folder containing all the digital ground photographs was placed on the client's computer to retain the proper hyperlink path name.

The next step required adding the CAD drawing and aerial photography layers to the application. The CAD drawings were spatially referenced when imported into ArcCatalog as feature classes, however, they were still not lined up properly. Each building drawing had to be geo-referenced to the correct location on the map. The photo was used early in the development process to assist in the digitizing effort, but it was not created as a layer initially, but made as a separate layer on the application that could be activated when necessary.

ArcGISTM was not the only software that was used to develop the application. For the 3D visualization of the high school, Google ${ }^{\mathrm{TM}}$ SketchUp Pro was utilized to generate a 3D 
perspective of the school. The first step in this development was to export the Montclair high school building shapefile to SketchUp Pro. Once the shapefile was successfully imported into SketchUp Pro, each building could then be extruded to an approximate building height. Following extrusion, the digital photographs, which were acquired during field collection, could be applied to the sides of the buildings. This process was called applying "skins" or textures to the building faces. This process was very tedious and time consuming because of the difficulty in accurately applying the textures to reflect a true real-world appearance. Once the 3D visualization of the Montclair High School was completed, the Google ${ }^{\mathrm{TM}}$ SketchUp Pro project was exported as a .kmz file format directly to Google ${ }^{\mathrm{TM}}$ Earth, which supported the 3D visualization. The client also requested that Google ${ }^{\mathrm{TM}}$ Earth be used for this part of the application. When opened, the Google ${ }^{\mathrm{TM}}$ Earth viewer automatically zooms into the 3D visualization that was created in Google ${ }^{\mathrm{TM}}$ SketchUp Pro.

The next step was to figure out a way to link to the Google ${ }^{\mathrm{TM}}$ Earth 3D visualization of the high school directly from the .mxd application. First, a custom tool was created in ArcMap. The Google ${ }^{\mathrm{TM}}$ Earth logo was used as the symbol for the tool. A custom Visual Basic code was required to create a link from the .mxd to Google ${ }^{\mathrm{TM}}$ Earth. Assistance for writing this code was obtained from Mr. Mark Deaton of ESRI ${ }^{3}$. Once the code was tested successfully, the user could simply click on the custom Google ${ }^{\mathrm{TM}}$ Earth button and automatically view the 3D visualization.

Code for Google ${ }^{\mathrm{TM}}$ Earth link:

$$
\begin{aligned}
& \text { Shell "'"C:IProgram Files\GooglelGoogle Earthlgoogleearth.exe"' } \\
& \text { "'C:LMHS_google_earthlMontclair_High_School_3D.kmz"'"', vbNormalFocus }
\end{aligned}
$$

Finally, a customized toolbar was created to simplify the user interface (Figure 17). This toolbar was designed to give the user easy-to-use tools that allow the user to navigate around the application and obtain all the needed information.

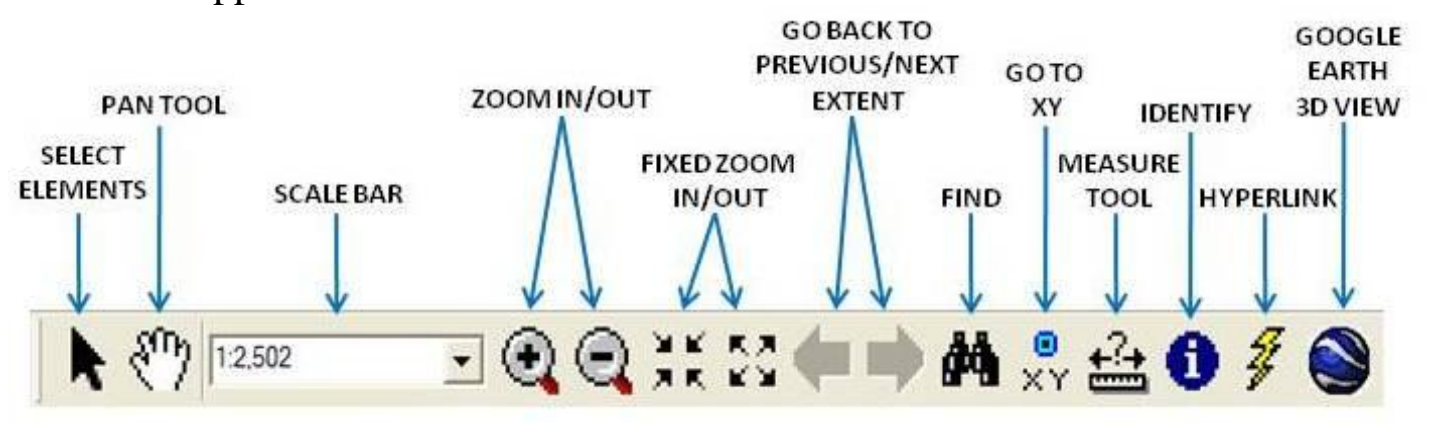

Figure 17. Customized toolbar designed for application

\footnotetext{
${ }^{3}$ Mark Deaton, Applications Prototype Lab, ESRI
} 
Once complete, the .mxd application was saved in a folder along with the file geodatabase, digital ground photos, Google ${ }^{\mathrm{TM}}$ Earth .kmz file, aerial photography, and CAD drawings. This folder could then be easily deployed onto the client's computers for use.

\subsection{Project Testing}

Following the construction of the application, the project entered the testing phase. This entailed using multiple testers of different experience levels completing a testing tutorial that was designed to check critical functions of the application. An example of the testing tutorial is located in Appendix A. Test subject experience levels included no GIS experience to at least eight years of GIS experience. It was important to include test subjects with no GIS experience because of the strong possibility that most of the application end-users will have zero GIS experience. The application was also tested by the client for accuracy and ease of use. Any issues raised by the test subjects and the client were successfully resolved. The next phase included the training and deployment of the application.

\subsection{Project Training and Deployment}

The project demonstration and training phase consisted of presenting the application and familiarizing the client with the application. The session took place at the Montclair city hall and lasted about 30 minutes in a one on one training style, and consisted of primarily showing the client the application and all of the functionalities.

The delivery of the application to the client included compilation of the application and associated data on a DVD (Figure 18). In addition to the DVD, a Standard Operating Procedures (SOP) guide or user manual was included that provides guidance to the user for operating the application. Since this is the first application completed solely for Montclair High School, the deployment strategy consisted of the "flip the switch" tactic for installation and implementation of the new system. This tactic is used to describe that the application is built for immediate operation following installation on the user's computer.

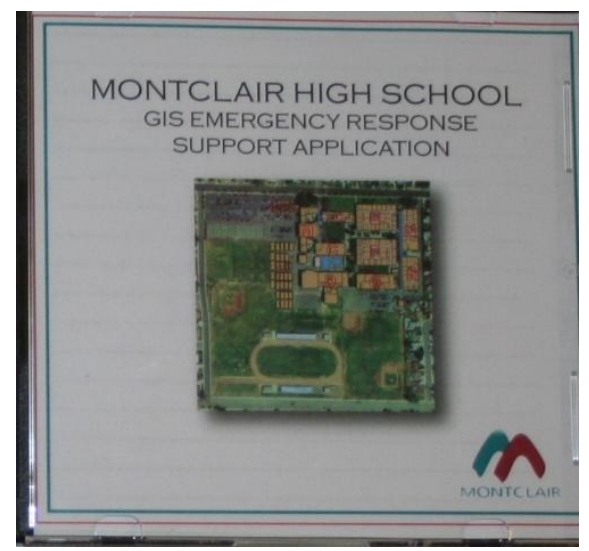

Figure 18. Example of the DVD with application submitted to the client 


\section{Application Functionality}

\subsection{Application Functionality}

First responders for the City of Montclair were in need of a system or application that could provide them with necessary information to respond to emergencies at Montclair High School. The system had to meet the needs of the emergency responder and most importantly this application had to be easy to use. This chapter discusses the overall functionality of the application and how easy it is to obtain critical information with the click of the computer mouse.

The users of this GIS emergency response application interact with it through interface developed almost entirely using commercial-off-the-shelf software from ESRITM. To start, the user selects the application on the desktop connects directly to an ArcMap window displaying the application (Figure 19). The application is first displayed showing a simple vector based map of the school's campus and surrounding neighborhood parcels. The names of the buildings are displayed for reference purposes. The application is also fully interactive; every layer of information in the product can be turned on or off depending upon the need for the information.

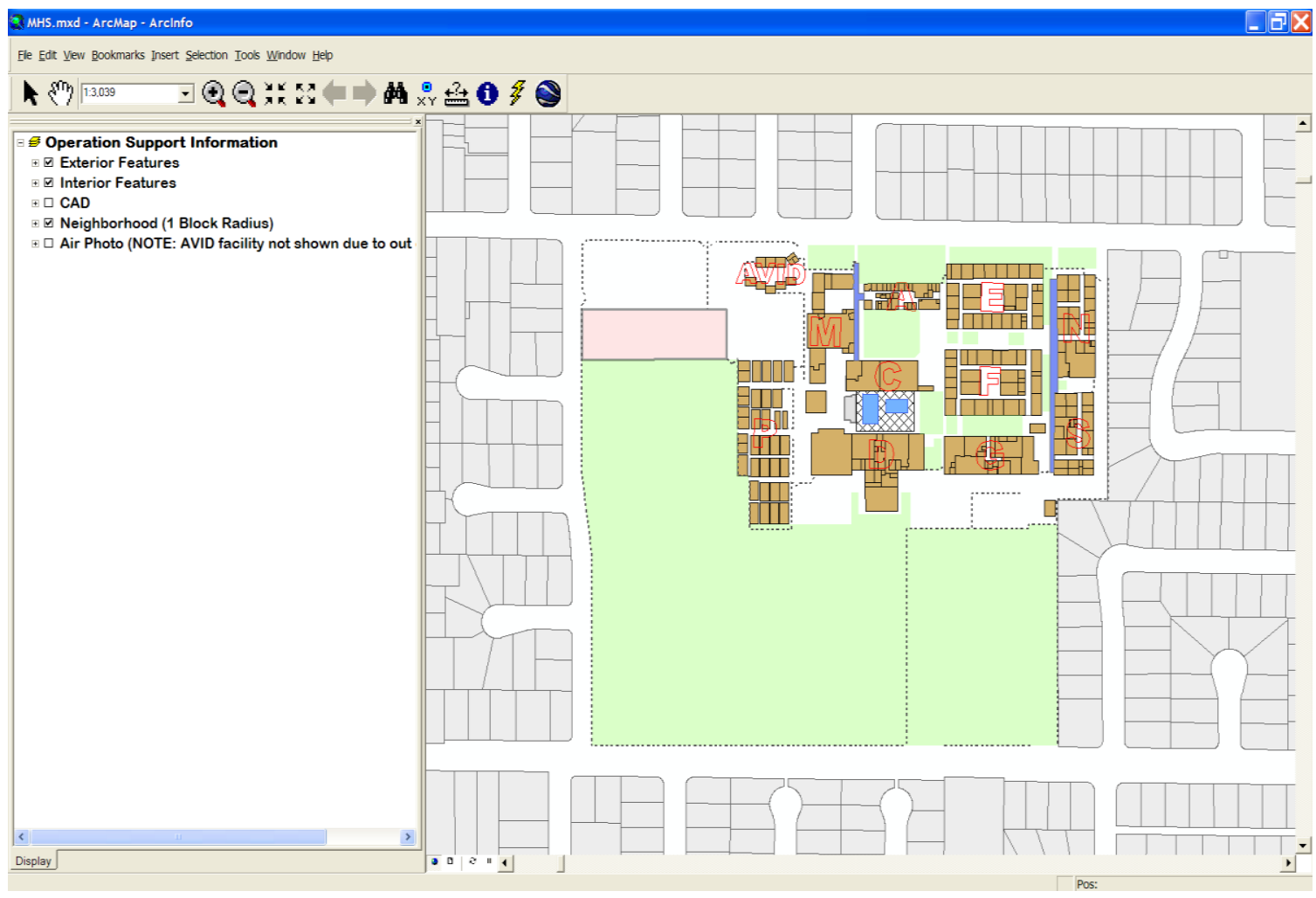

Figure 19. Application startup view 
This application was equipped with a customized toolbar containing specific tools that allow the user to easily navigate through the system. The customized toolbar and the identification of the tools are shown in Figure 20.

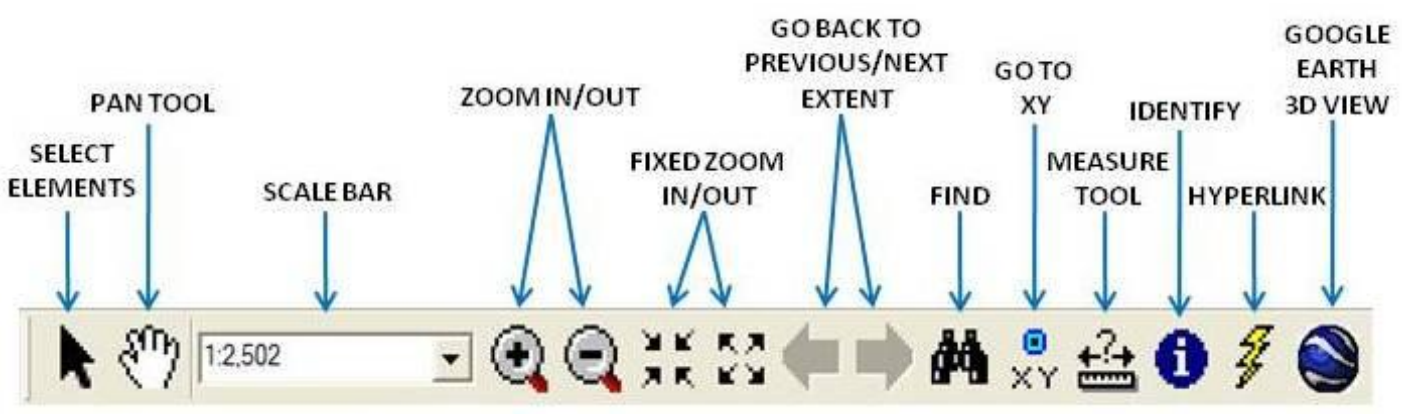

Figure 20. Customized toolbar designed for application

The user has an option of selecting a variety of information layers in the table of contents window, which can further display the added information after checking the layer to turn it on. The first layer option in the table of contents is the Exterior Features layer. Under that layer are sub-layers which can be further selected to display specific location information. The first sub-layer that can be activated is the Perimeter Road View. When activated symbols display on the interface identifying specific views of the perimeter roadways around the school's campus. Each point symbol can be selected by using the identify tool (Figure 21). When the point is selected an identify box first appears. This identify box provides the user with valuable information about the point such as: location, name, azimuth, elevation, and a digital ground photography hyperlink. The photo can be accessed by selecting anywhere on the hyperlink line inside the box and will display showing the view according to the point the photograph was taken and the azimuth of the photo as indicated in the identify box. 


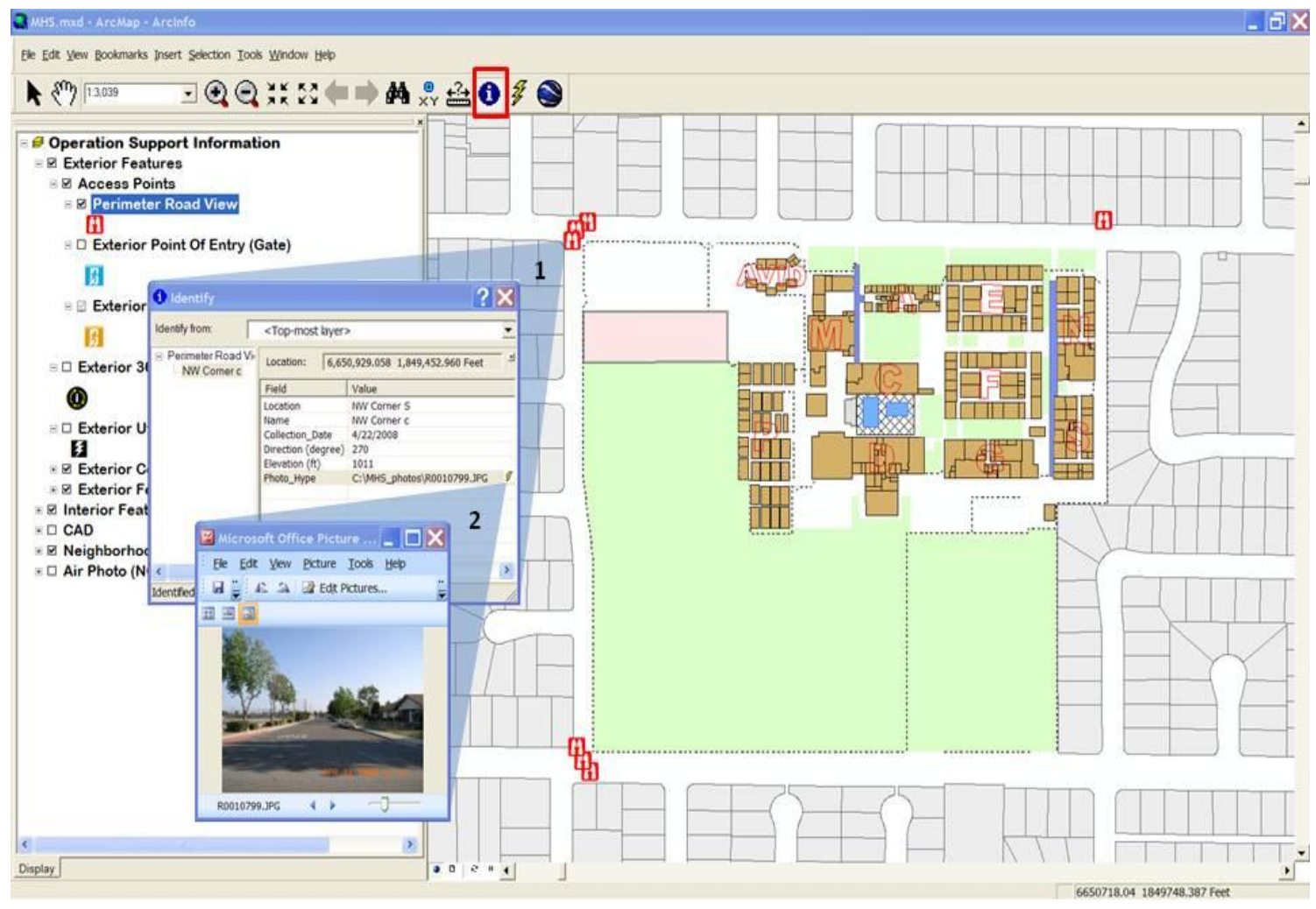

Figure 21. Two-step process to view information of Perimeter Road View

This same process can also be performed for the Exterior Point of Entry (Gate), Exterior Point of Entry (Doorway), and Exterior Utilities layers as shown in Figures $22-24$. 


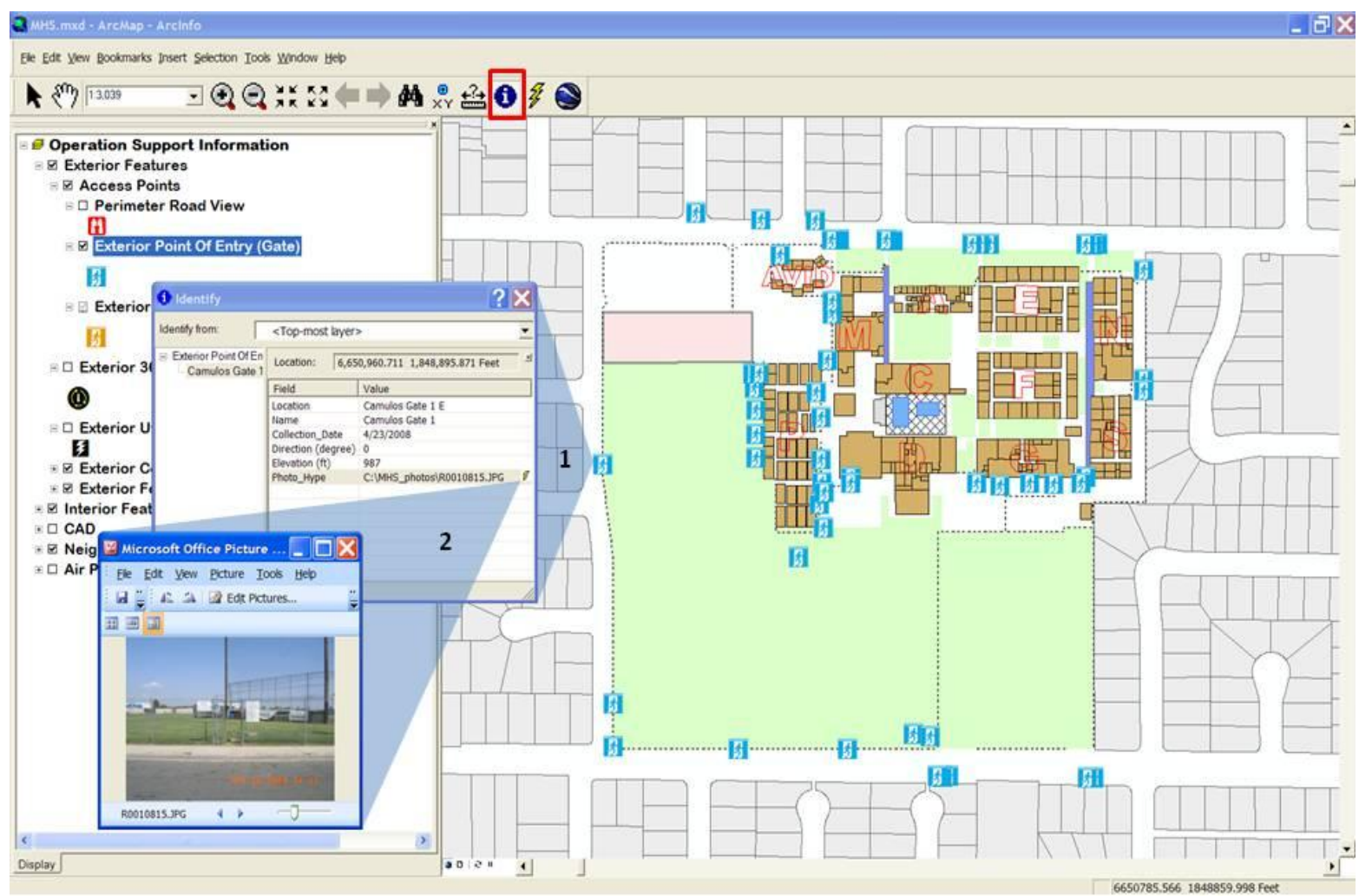

Figure 22. Two-step process to view information of Exterior Point of Entry (Gate)

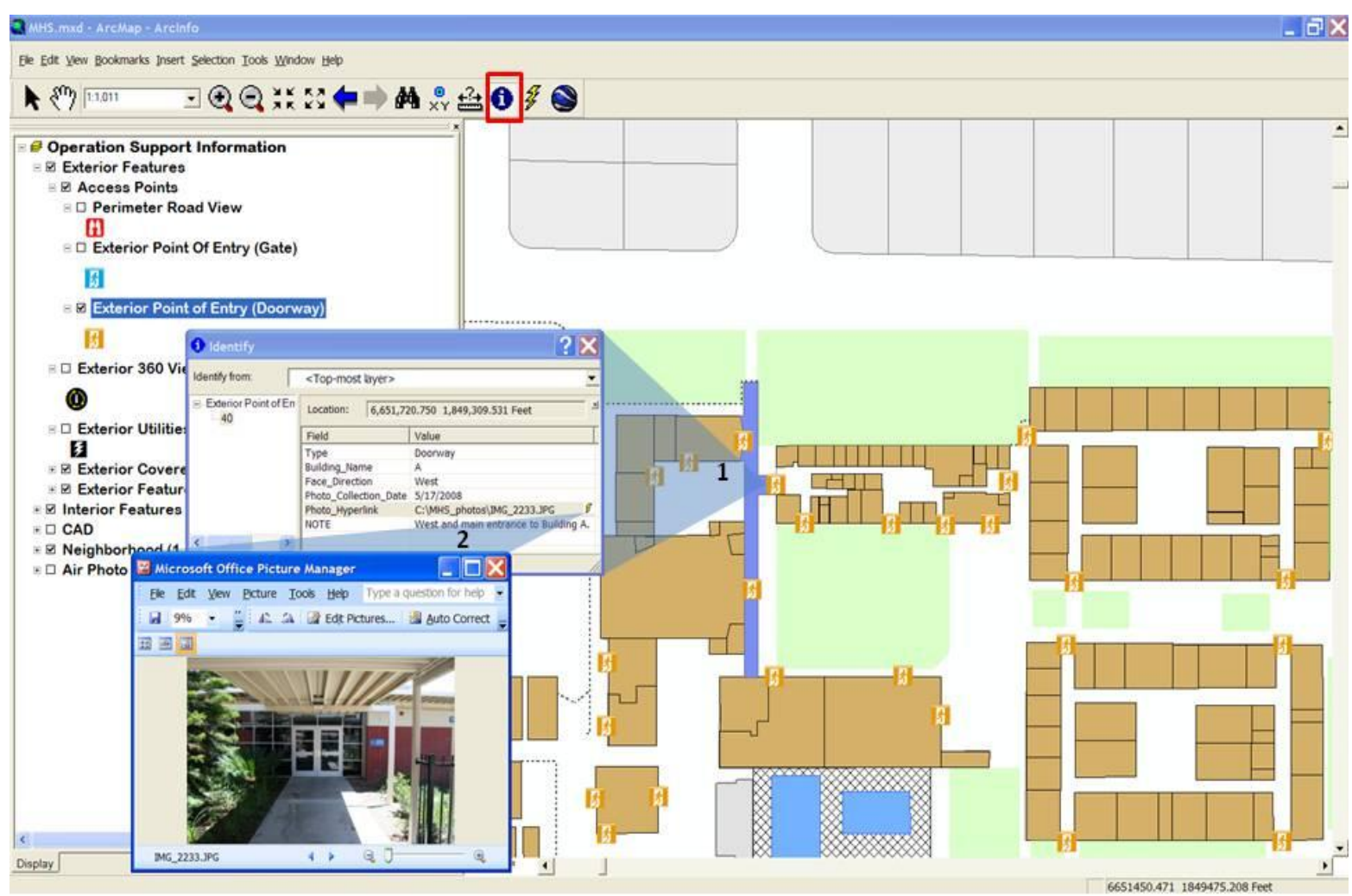

Figure 23. Two-step process to view information of Exterior Point of Entry (Doorway) 


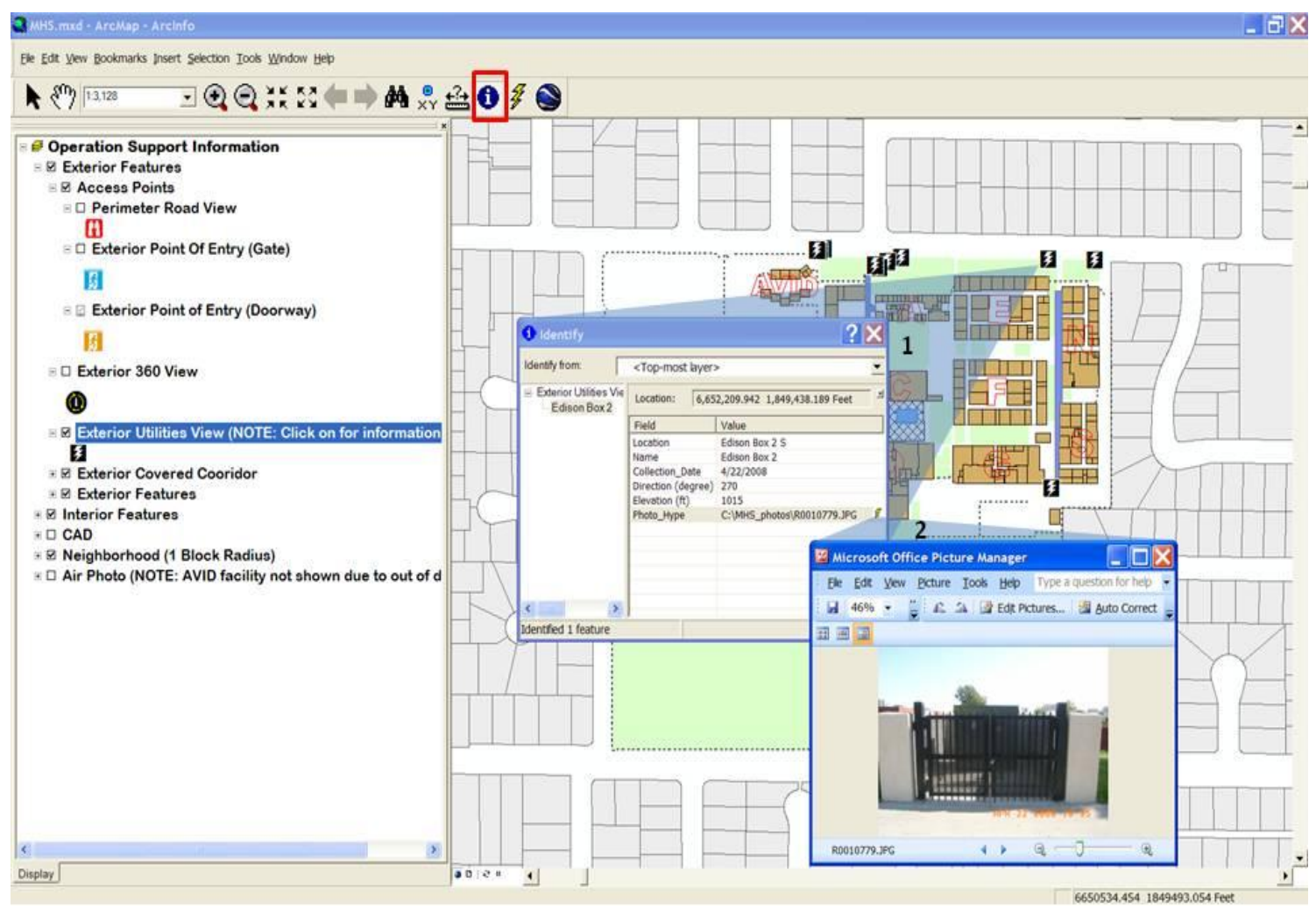

Figure 24. Two-step process to view information of Exterior Utilities View

The user also has the option of activating the Exterior 360 View layer for unique $360^{\circ}$ visual from the point selected (Figure 25). The user must, as with previous functions, select the point on the map with the identify tool to reveal the identify box. To activate the graphic, the user must select the hyperlink line inside the identify box. The $360^{\circ}$ photo is displayed using a fully interactive QuickTime viewer. The user can zoom in and out, and pan across the image. 


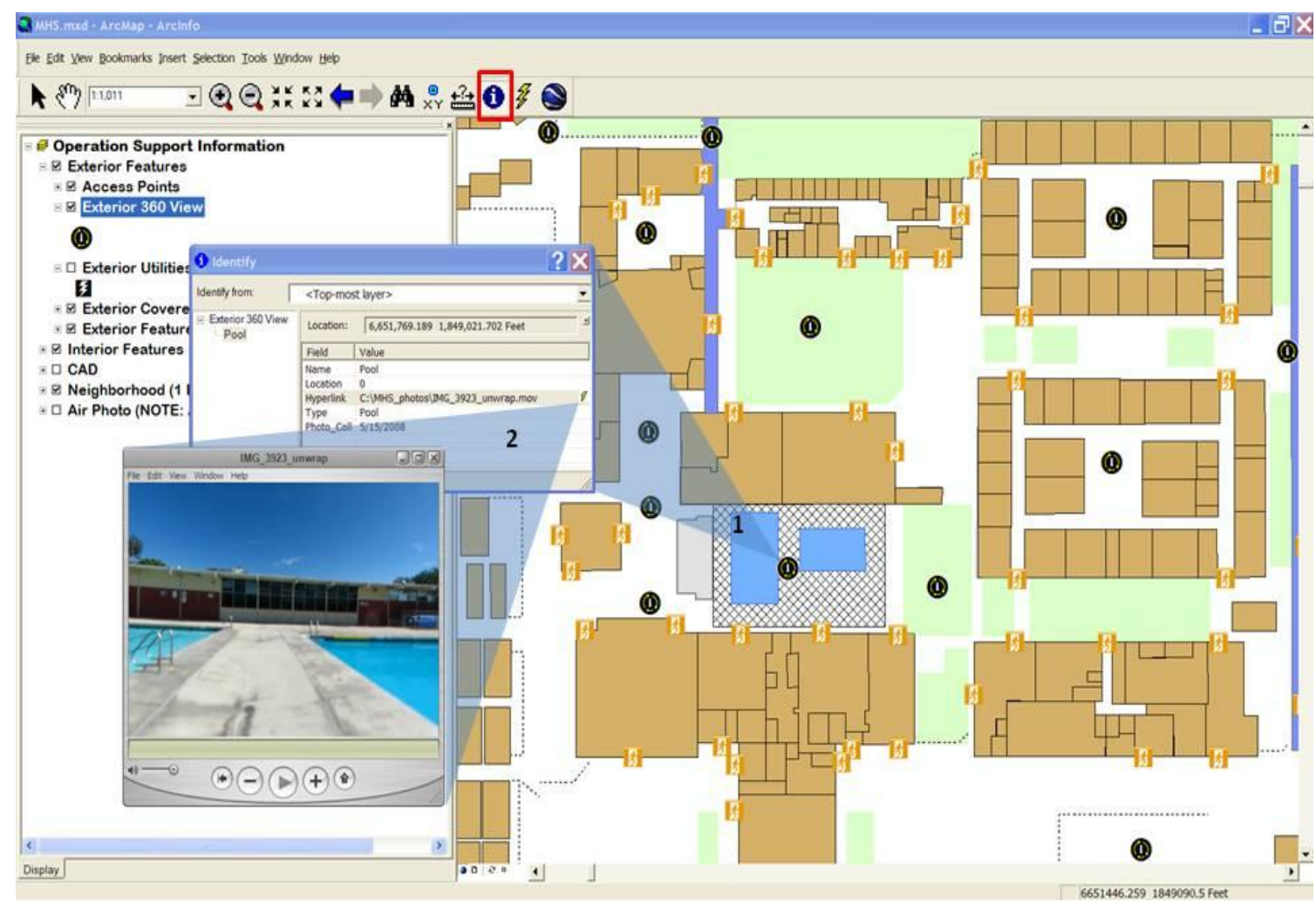

Figure 25. Two-step process to view information of Exterior 360 View

The second layer of information is the Interior Features layer, which can be expanded to reveal a number of sub-layers. All of the point information layers are scale dependent. When zoomed in within 1:1,000 or less, all the point features will be displayed accordingly. The first sub-layer of point information available to the user is the Interior 360 View layer. This is similar to the Exterior 360 View, except that the QuickTime viewer is instantly accessible by clicking on the point. When the user selects the hyperlink tool on the customized toolbar, a red dot is centered on each $360^{\circ}$ view point. This indicates that the hyperlink is active. The user then selects the point to activate the QuickTime viewer and photo as shown below in Figure 26. 


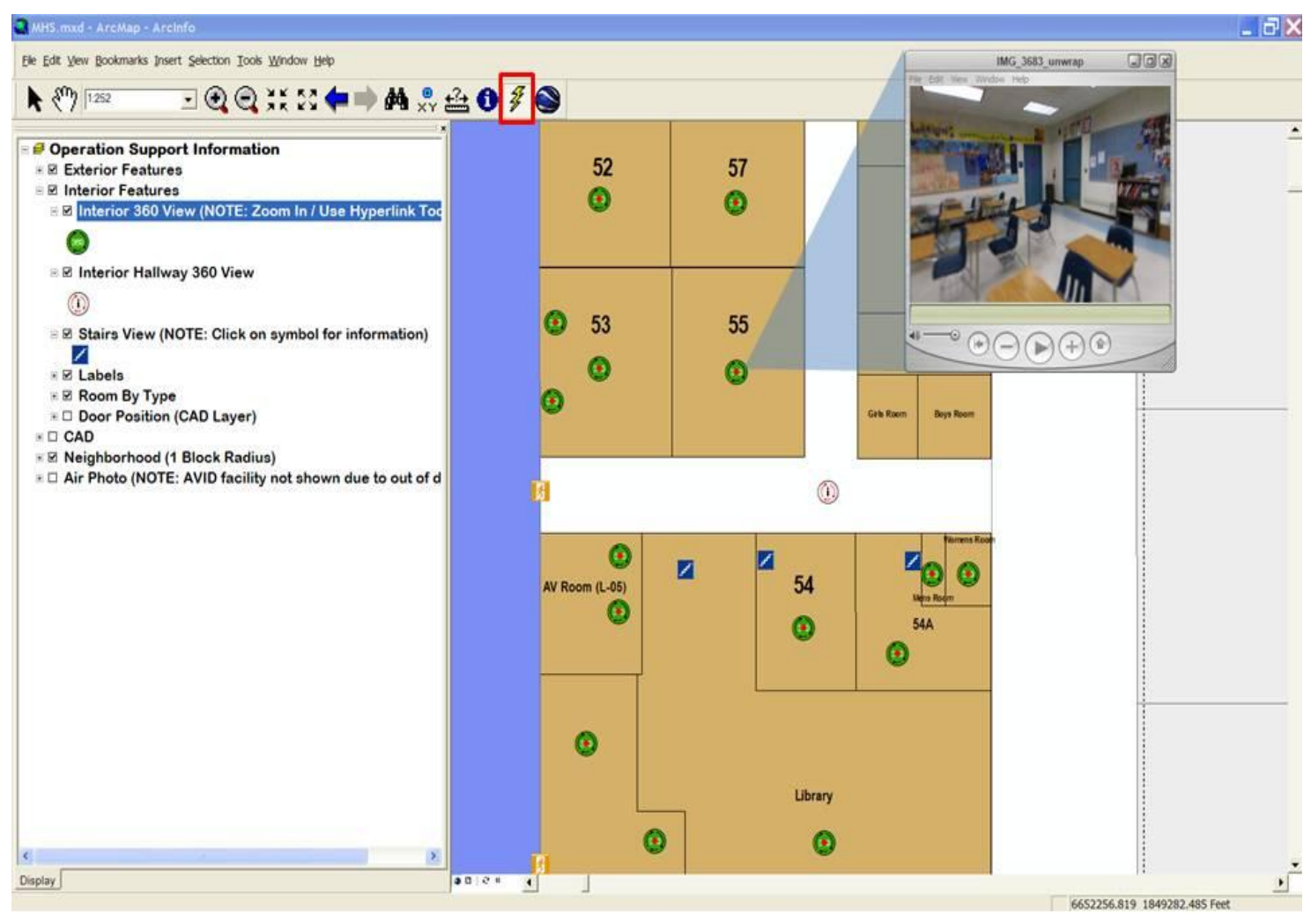

Figure 26. Process of selecting Interior 360 View by hyperlink tool

The user can also access information pertaining to the hallways located inside each building on campus. This can be done by using the identify tool and selecting a hallway point location indicated by the point symbol. Once selected, the identify box appears with information about the hallway and a $360^{\circ}$ photo hyperlink. The user can select the photo hyperlink on the identify box and the QuickTime viewer will appear, as shown in Figure 27. 


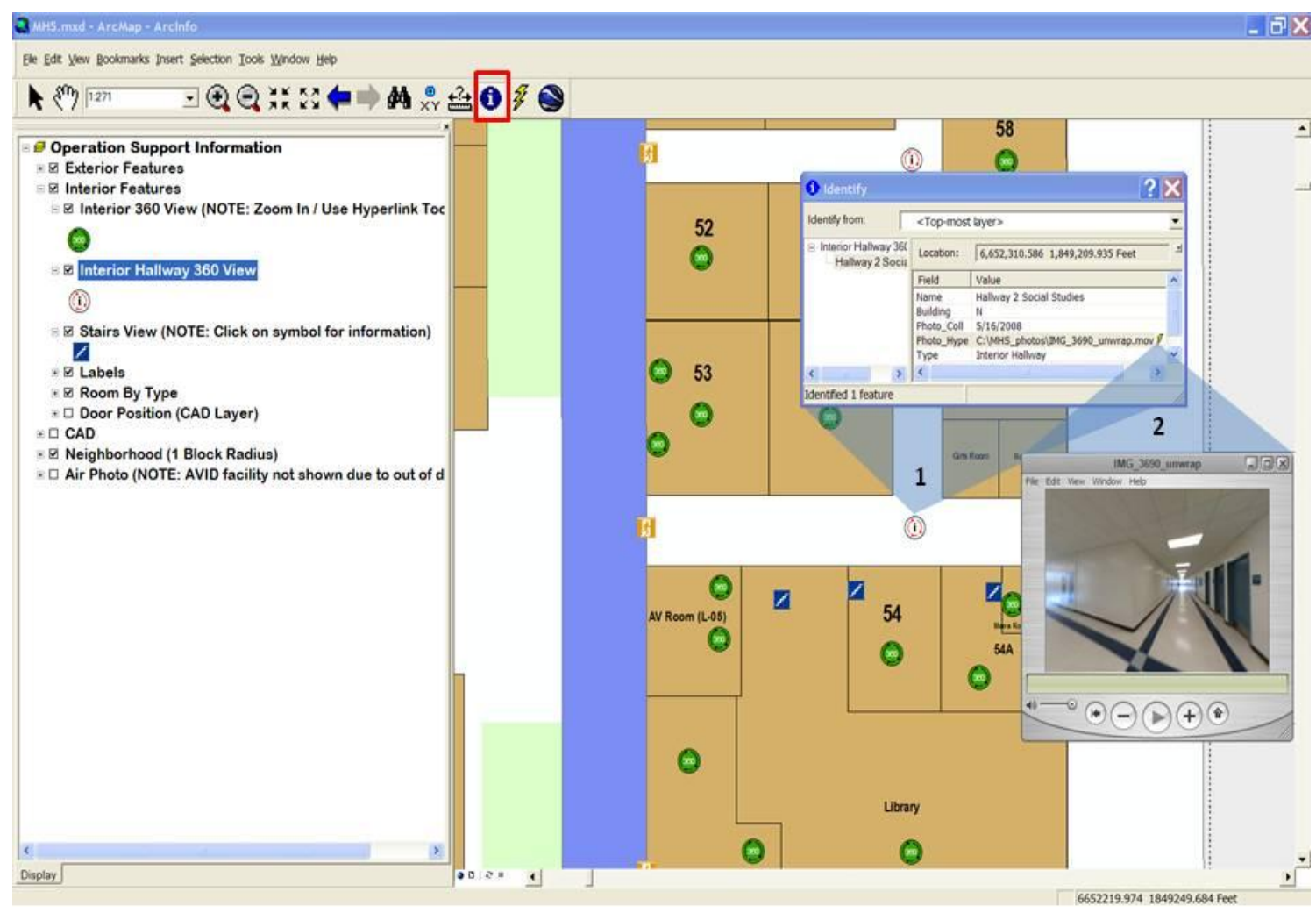

Figure 27. Two-step process of obtaining information of Interior Hallway 360 View

The user can also access information about any staircase inside the school. Using the identify tool, the user selects the stairs point on the application to reveal the identify box with information about the stairs location. The user can also access a photo hyperlink to reveal the stairs as viewed when entering the facility (Figure 28). 


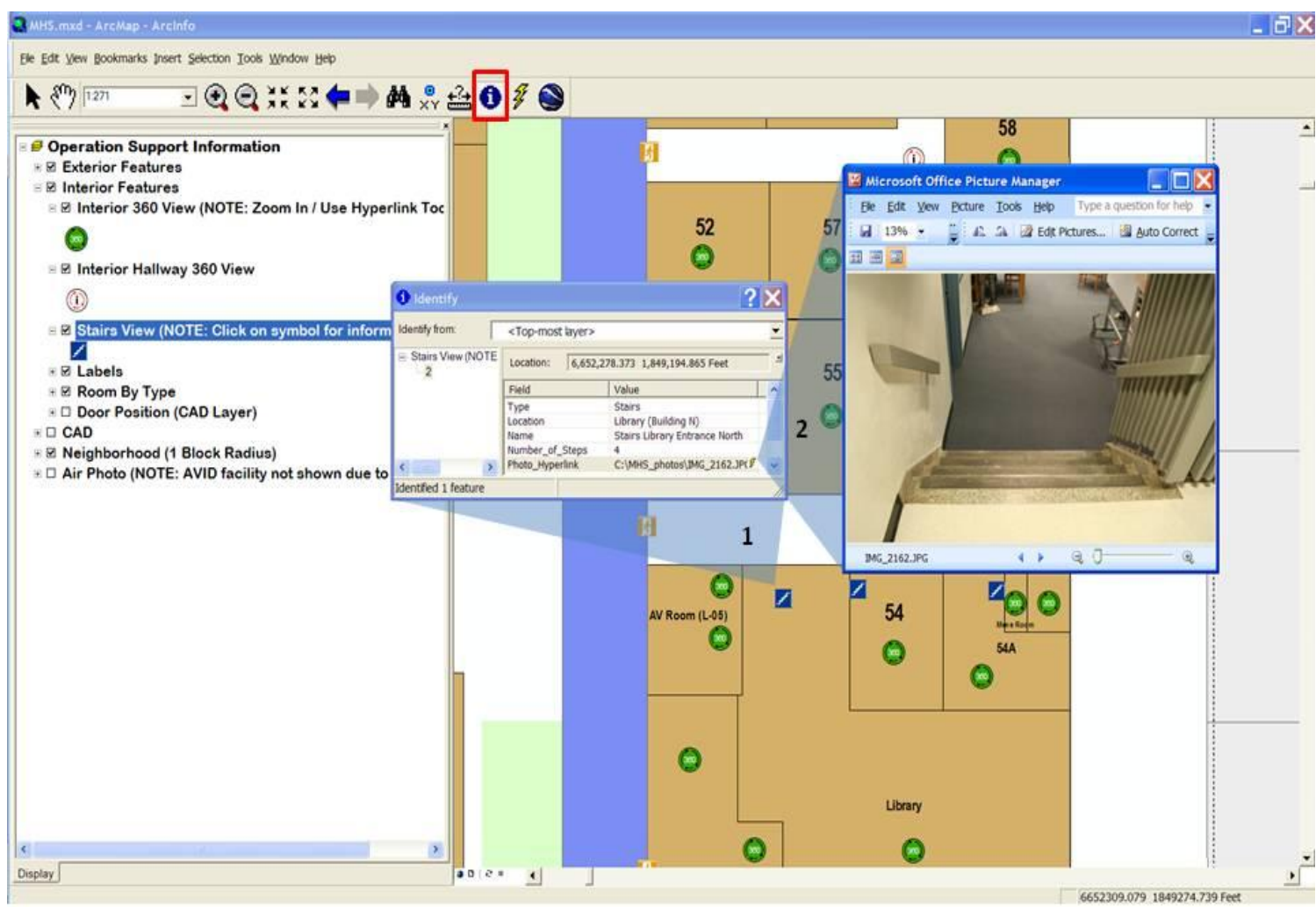

Figure 28. Two-step process of obtaining information of Stairs View

Finally, at any time the user can use the identify tool to select an interior facility polygon to reveal the identify box containing information and all the photo hyperlinks associated with that facility. This is a secondary way of accessing information about the facility and viewing photos about the facility (Figure 29). 


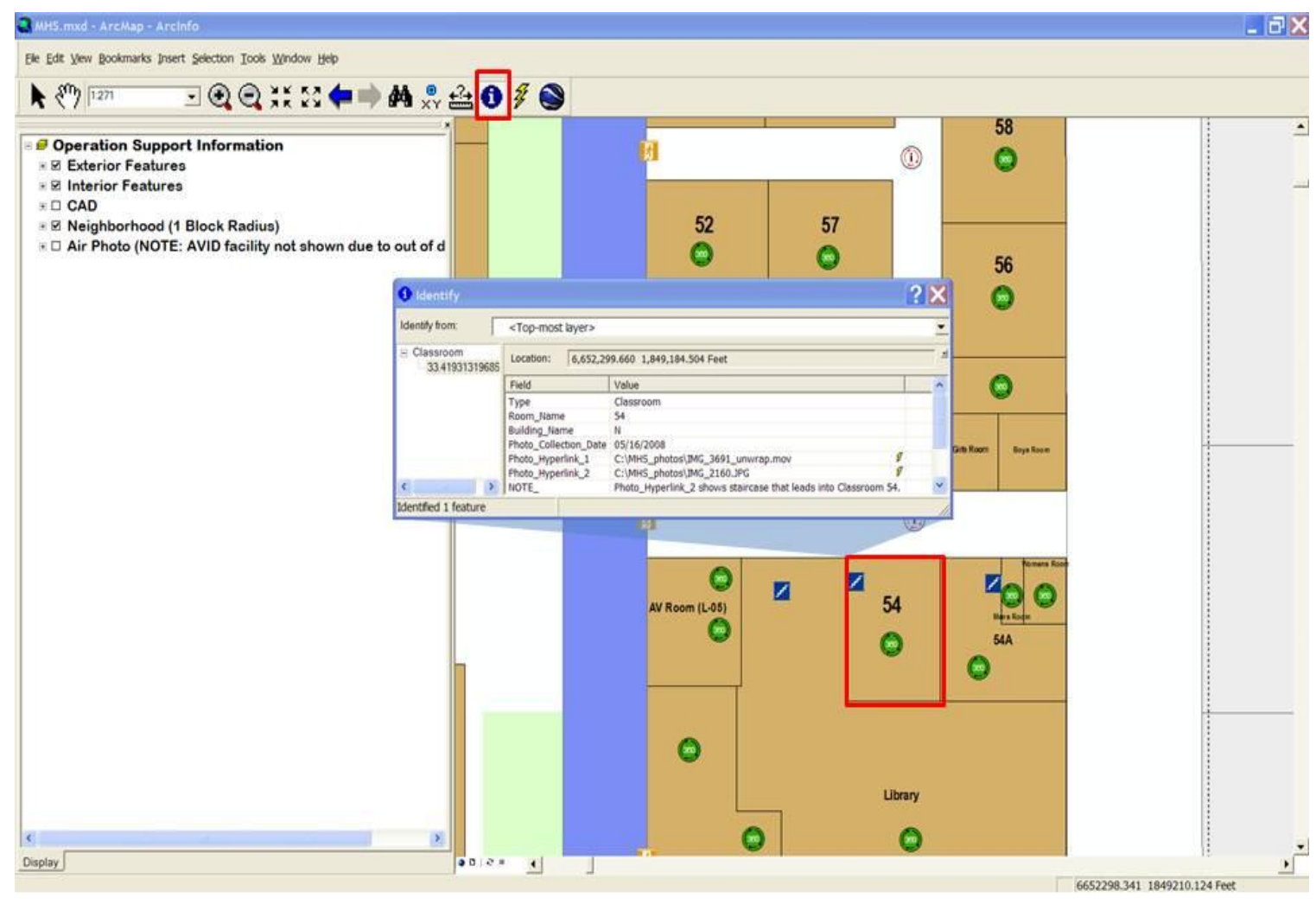

Figure 29. Selection of facility polygon to reveal identify box

The following two layers can be activated individually to present the user with unique information. The first is the CAD drawing layer. The user can turn off the Exterior and Interior Features layers to reveal the drawings. When activated, each building drawing is displayed showing doorway positions and swing directions, as well as wall structures (Figure 30). 


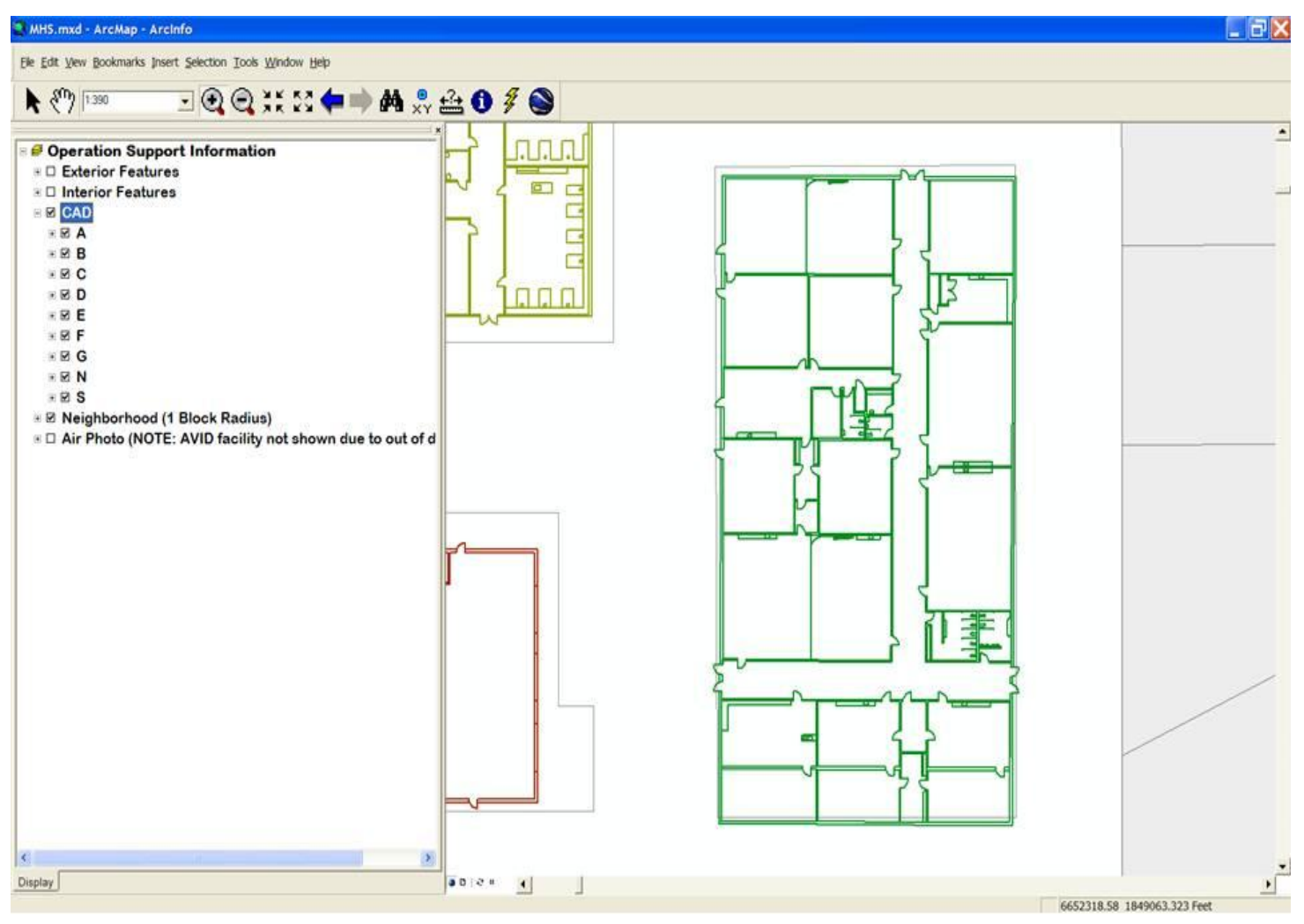

Figure 30. CAD drawing layer is activated to reveal building drawing

The second and final layer of information is the Air Photo layer. When activated, this layer presents the user with a bird's eye view of the high school campus and the surrounding environments (Figure 31). 


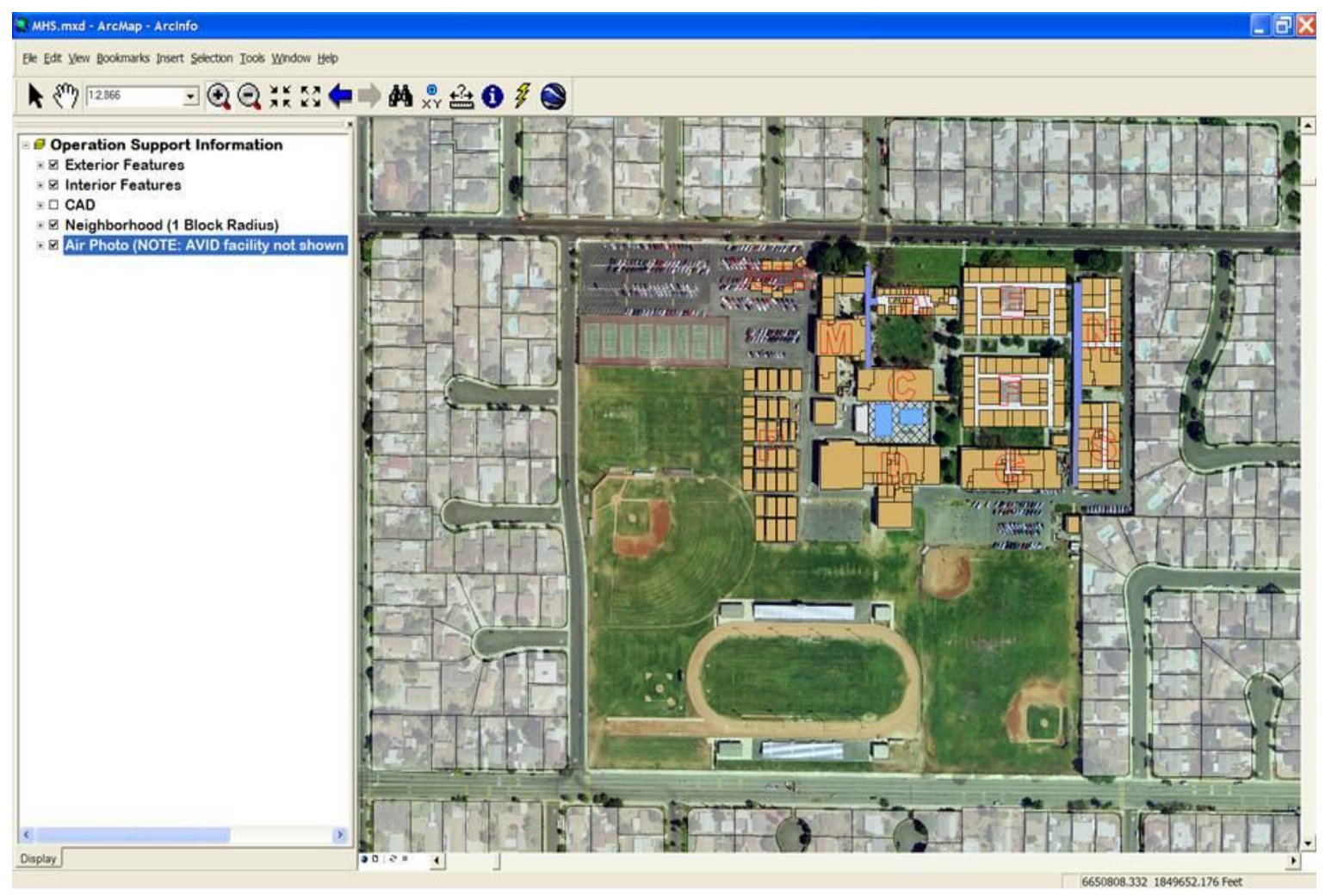

Figure 31. Air Photo layer activation reveals photo of high school and surroundings

A unique feature of this emergency response application is the link to the 3D visualization of the Montclair high school through Google ${ }^{\mathrm{TM}}$ Earth. The user can select the Google ${ }^{\mathrm{TM}}$ Earth button on the customized toolbar to access the visual. Once the button has been selected, the Google ${ }^{\mathrm{TM}}$ Earth viewer automatically appears and zooms in directly to the 3D visualization of the high school that was created in Google ${ }^{\mathrm{TM}}$ SketchUp (Figure 32). 


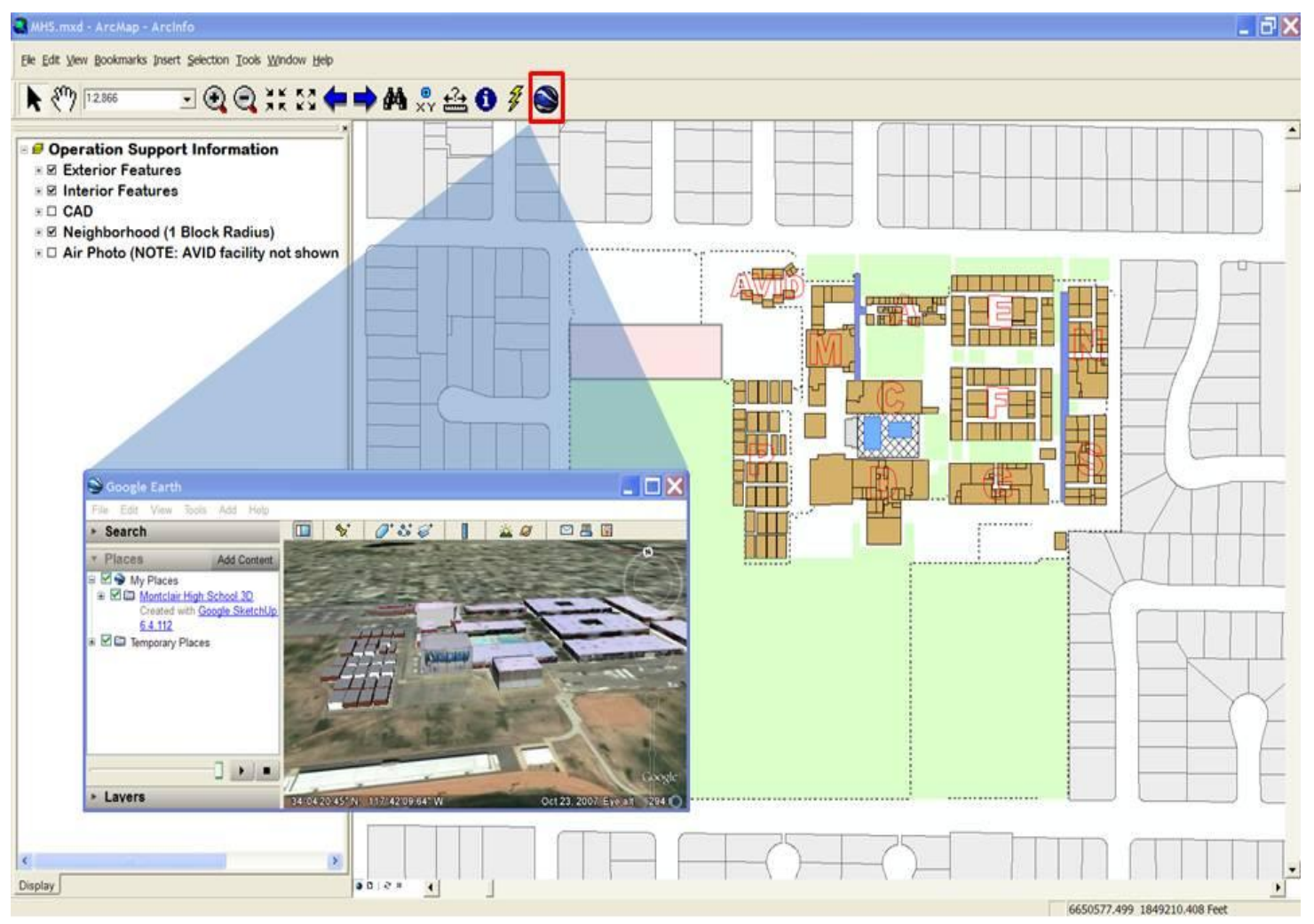

Figure 32. Google Earth 3D perspective of the Montclair High School

At this point, the user can interact with the $3 \mathrm{D}$ visual in Google ${ }^{\mathrm{TM}}$ Earth by zooming in and out, and panning around the visual (Figure 33). This feature provides a unique perspective to the user. 


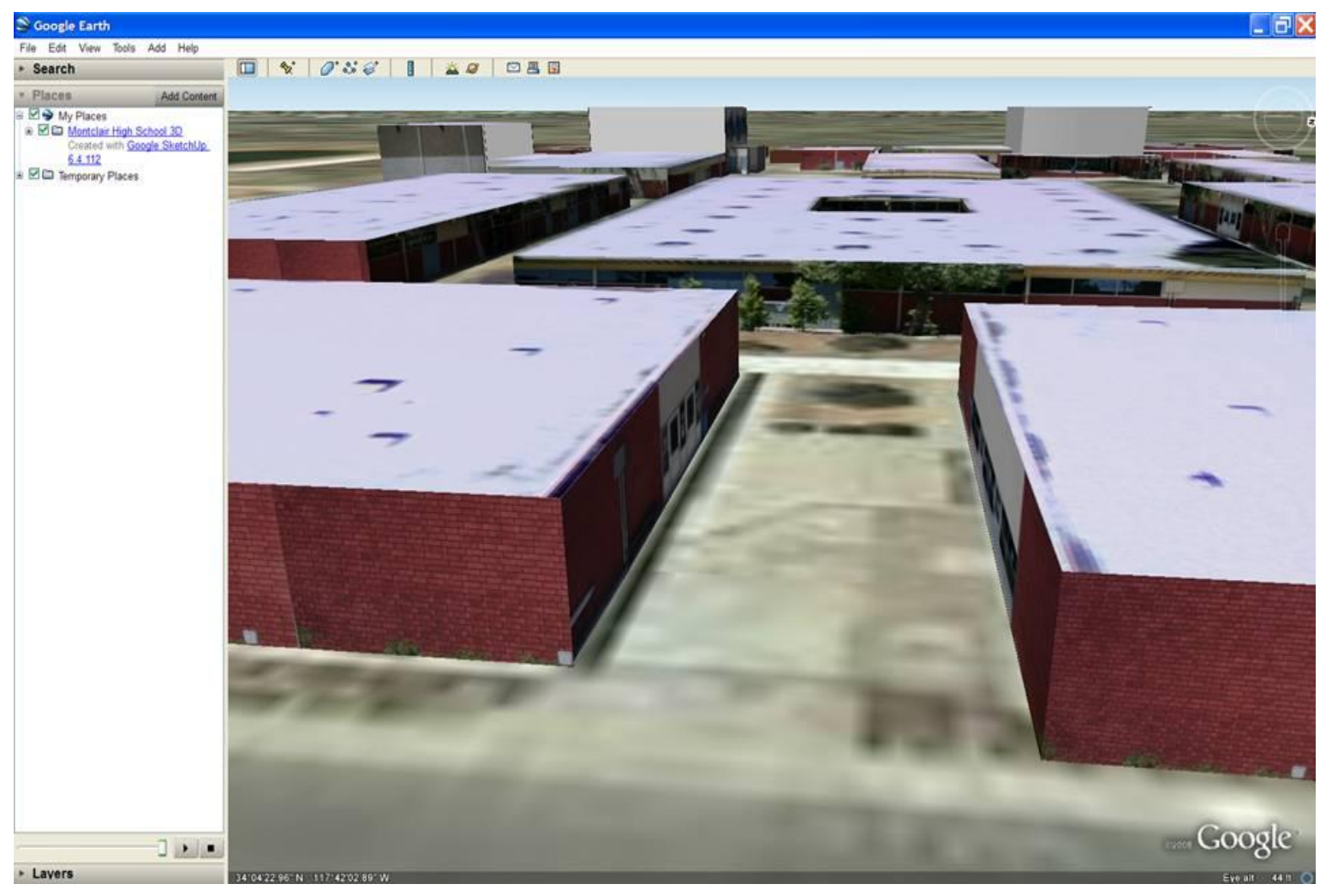

Figure 33. Zoomed in 3D perspective of Montclair High School 


\section{Conclusions}

The Montclair, California first responders were in need of a better system to react to a potential crisis at Montclair High School. The application designed for this project served that purpose. It was the goal of this project to use ESRI ${ }^{\mathrm{TM}}$ ArcGIS $^{\mathrm{TM}}$ software, Google ${ }^{\mathrm{TM}}$ Earth, and Google ${ }^{\mathrm{TM}}$ SketchUp to create an efficient and easy to use application that answered the client's requirements in support of Montclair emergency response. This goal was accomplished and was fully accepted by the client.

\subsection{Future Considerations}

During the development of this application other project ideas arose, most of which were outside the scope for this project. The enormity of the technology world today presents creators of applications that support emergency response with a multitude of thoughts to enhance applications. A number of ideas were discussed with the client, but the project schedule, timeframe, and the client's limited access to certain technology prevented these plans.

The idea was initially discussed to make the application a web-based project using ESRI ${ }^{\mathrm{TM}}$ ArcServer. This option would be ideal for deploying to multiple computers, especially to the police and fire vehicles with web access. Upon further research and interviews with the client, it was determined to be impossible at this time. The vehicles are indeed equipped with web accessible computers; however, the band width in the vehicles is not strong enough to handle the application. In addition to the connectivity, the LCD monitors are also not designed to handle images that this application contains. The images would burn onto the screen. Due to the high cost of upgrading their vehicles, the City of Montclair was not willing to commit to upgrades to support the application. If the vehicles do undergo technological enhancement and a larger bandwidth is established, this idea could be ideal.

Another idea that was considered included incorporating live video feeds from the high school's robust video camera network. The school has an extensive system of camera monitors that can observe all areas of the school campus. Incorporating this feature in an emergency response application could provide valuable real-time intelligence to personnel in the field.

Future applications can really benefit from Google ${ }^{\mathrm{TM}}$ SketchUp. The concept of 3D visualization provides the user with a realistic appearance. One way to improve on the $3 \mathrm{D}$ visualization would be to acquire improved and updated CAD drawings for the buildings, and then create the 3D model using these drawings. This detailed model would show individual rooms and facilities based upon the drawings (Figure 34). It also would be extremely useful to incorporate the digital ground photography, both $360^{\circ}$ and still, used in this application to enhance the functions. 


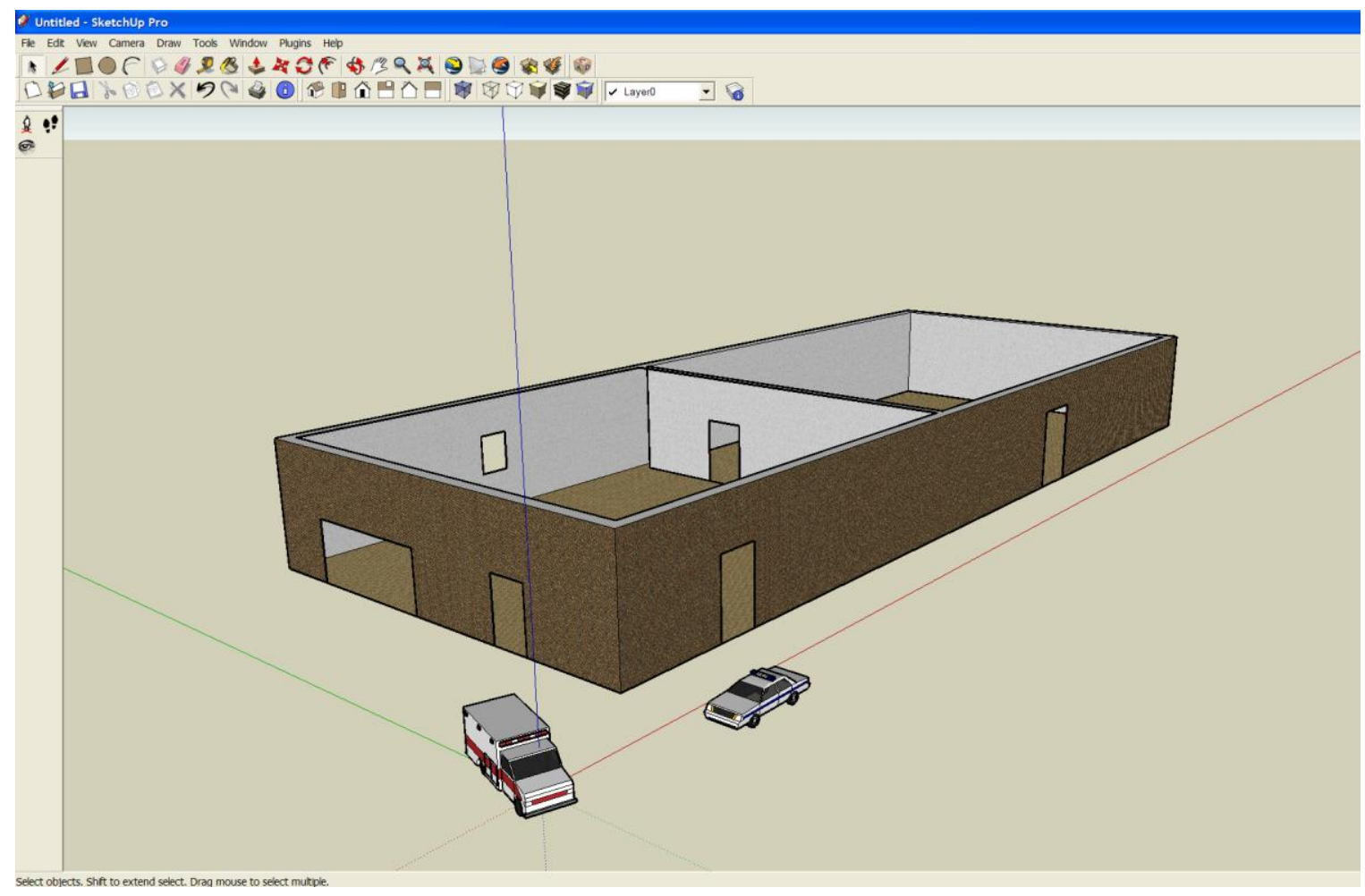

Figure 34. Example of Google ${ }^{\mathrm{TM}}$ SketchUp interior capabilities

As previously mentioned in section 4.2 Field Collection, the 0-360 Unwrapper ${ }^{\mathrm{TM}}$ software program used to unwrap, convert, and compress all the $360^{\circ}$ photographs introduced a loss in resolution and quality when each photograph was saved in .jpg format. For future field collection, the resolution of each photograph may possibly be enhanced by taking the photographs at full resolution or in a tiff file format. An increase in quality of resolution would prove to be of more value to the application user by providing a more detailed visual of the point of interest.

For future use of the $360^{\circ}$ camera lens during field collection, it would be very important to note the direction that each $360^{\circ}$ photograph begins when viewed in a QuickTime viewer. When the user selects a point and views the $360^{\circ}$ photograph, it is extremely important that the user understands the direction at which he or she is initially looking at. For collection purposes, this can easily be done by understanding at which point on the $360^{\circ}$ lens the photograph begins. A suggested technique would be to make a white erasable mark or place a small piece of white tape on the top, black portion of the lens (Figure 35). It is very important to not mark the lens or cover any portion of the lens with tape. During collection, the mark should face the main point of entry into the facility. This would be the first view the user would see upon selection of the point and QuickTime viewer. When creating symbology for the points, it would be very beneficial to indicate on each point symbol the direction the QuickTime viewer begins. This can be accomplished by creating a triangular symbol pointing in the direction that viewer begins. 


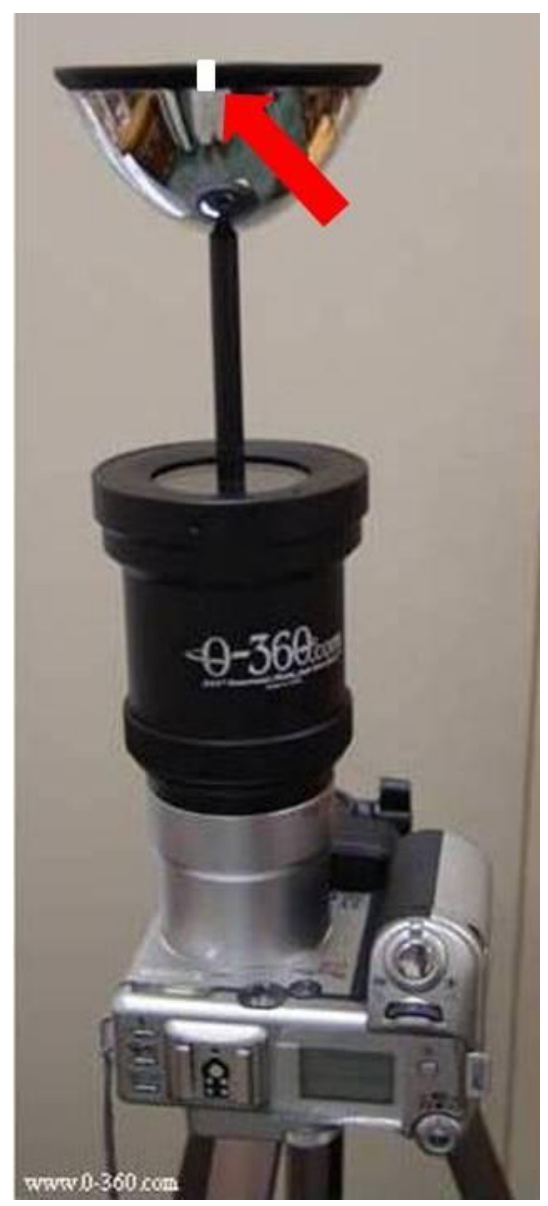

Figure 35. White marking on 0-360 lens for collection purposes.

Future applications would benefit from easier access to photographs during point selection, while still displaying the information box for the selected point. In other words, when the user selects a point on the application the information box and the photograph appear simultaneously. This would remove the step the user has to select the photograph hyperlink in the information box. Time is a very important factor when responding to an emergency situation. Removing one step in the process allows the critical information to arrive to the emergency responder in a timely fashion.

At the initial requirements meeting in January 2008, the client discussed the idea that this project could be focused on a number of facilities located around Montclair, including the junior high school, City Hall, and possibly the newly constructed police station. After the completion of this project for Montclair High School, it would be very feasible and highly recommended that future applications be considered for other Montclair facilities.

An idea for a rapid deployment field kit was also addressed. This field kit would include a customized, hard-plastic Pelican ${ }^{\text {TM }}$ case that contained a field laptop and hardcopy maps, among other necessary hardware. This field kit would employ emergency response applications for the Montclair High School and other facilities. 



\section{List of References}

Baker, T. R. (2007). Tactical Entry and Emergency Response: GIS Goes into the Field. University of Redlands, Redlands.

Bruzewicz, A. J. (2003). Remote sensing imagery for emergency management. In S. L. Cutter, Richardson, D. B., Wilbanks, T.J. (Ed.), Geographical Dimensions of Terrorism (pp. 87-97): New York, Routledge.

Cahan, B., Ball M. (2002). GIS at Ground Zero: Spatial technology bolsters World Trade Center response and recovery. GEOWorld, 15(1), 26-29.

Curtis, A., Mills, J., Blackburn, J., Pine, J. (2006). Hurricane Katrina: GIS Response for a Major Metropolitan Area. Boulder, CO: Natural Hazards Center, Institute of Behavioral Science, 180, 1-7.

Cutter, S. L. (2003). GI Science, Disasters, and Emergency Management. Transactions in GIS, 7(4), 439-445.

Dague, S. (2008, January 23). MIP interview and discussion with client (Montclair, CA).

Finnell, J. (2006, 04/2006). New Technology Helps Emergency Officials Avert School Tragedy. 9-1-1 Magazine, 48-50.

Galloway, G. E. (2003). Emergency preparedness and response: Lessons learned from 9/11. In S. L. Cutter, Richardson, D. B., Wilbanks, T.J. (Ed.), Geographical Dimensions of Terrorism (pp. 27-34): New York, Routledge.

Knapp, S. (2008, February 15). President Knapp's Message Regarding Tragedy at Northern Illinois University. In F. Students, and Alumni (Ed.). (Washington D.C.) President of the George Washington University.

Lee, J. (2006). A Three-Dimensional Navigable Data Model to Support Emergency Response in Microspatial Built-Environments. Annals of the Association of American Geographers, 97(3), 512-529.

Prepared Response Inc. (2008). Enhancing Your Power to Respond. Retrieved October 2, 2008, from http://www.preparedresponse.com

Reed, B. (2007). Mapping the Future of Emergency Response. Northwest Education, 13(1), 26-29.

Thomas, D. S. K., Cutter, S.L., Hodgson, M.E., Gutekunst M., and Jones, S. (2002). Use of Spatial Data and Technologies in Response to the September 11 Terrorist Attack. Boulder, CO: University of Colorado, Natural Hazards Research and Applications Information Center, Quick Response Bulletin, 153. 



\section{Appendix A}

\section{Testing Tutorial for Montclair High School Emergency Response GIS Application Application Setup (Prior to testing):}

1. Click on the C_Drive folder. Copy the two folders (MHS_Google ${ }^{\mathrm{TM}}$ _earth \& MHS_photos) to your computer's C:/drive.

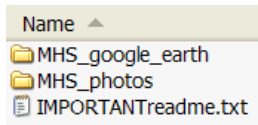
Size $\mid$ Type File Folder File Folder $1 \mathrm{~KB}$ Text Document

2. Copy the MIP folder (highlighted in blue) to the desktop.

\begin{tabular}{|c|c|c|}
\hline Name $\triangle$ & Size & Type \\
\hline $\begin{array}{l}\text { C_Drive } \\
\text { MIP }\end{array}$ & & $\begin{array}{l}\text { File Folder } \\
\text { File Folder }\end{array}$ \\
\hline IMPORTANTreadme.txt & $1 \mathrm{~KB}$ & Text Document \\
\hline
\end{tabular}

3. Once copied to the desktop, open the MHS.mxd file inside the MIP folder to initiate the application.

4. IMPORTANT: Google ${ }^{\mathrm{TM}}$ Earth button will not be displayed upon start-up, and must be applied to the MHS_ER toolbar. To accomplish this:

a. Go to Tools - Customize

b. Click the Commands tab, and scroll down to the [UIControls] selection on left side.

c. On the right side, select the ProjectUIButtonControl1, and drag the button to the MHS_ER toolbar.

d. Keep Customize window open, and right click the new button to change button image.

e. Select browse to the MIP folder that was copied to the desktop. Under the MIP folder, select the Google ${ }^{\mathrm{TM}}$ Earth logo (highlighted in blue to right).

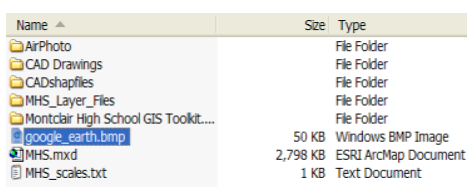

f. In order for the Google ${ }^{\mathrm{TM}}$ Earth link to work, the correct Google ${ }^{\mathrm{TM}}$ Earth application path code must be applied to the button source shown below and highlighted in blue. The source can be accessed by right clicking on new Google ${ }^{\mathrm{TM}}$ Earth button, and with the Customize window still open, select View Source. Identify the correct path for Google ${ }^{\mathrm{TM}}$ Earth on computer, and if different than the current setting, replace path.

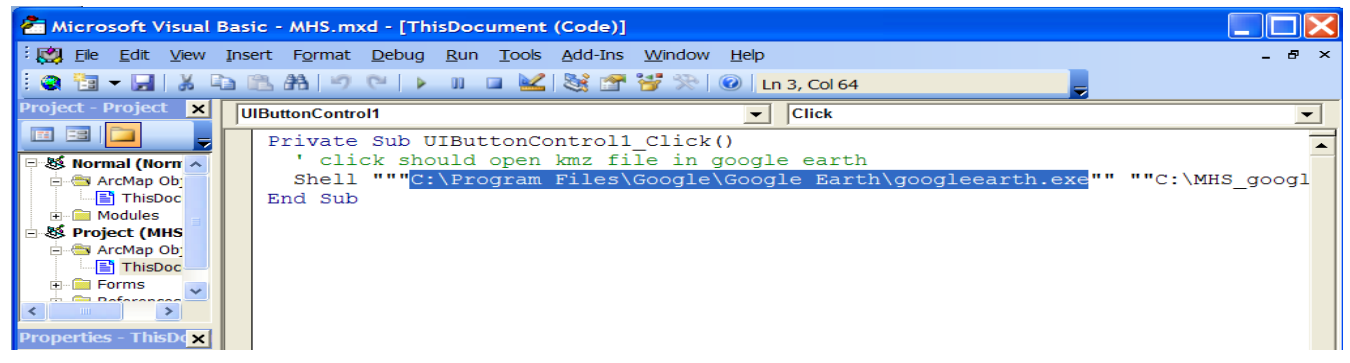


5. After opening the MHS.mxd inside of the MIP folder and setting up the Google ${ }^{\mathrm{TM}}$ Earth button, the application below will appear:

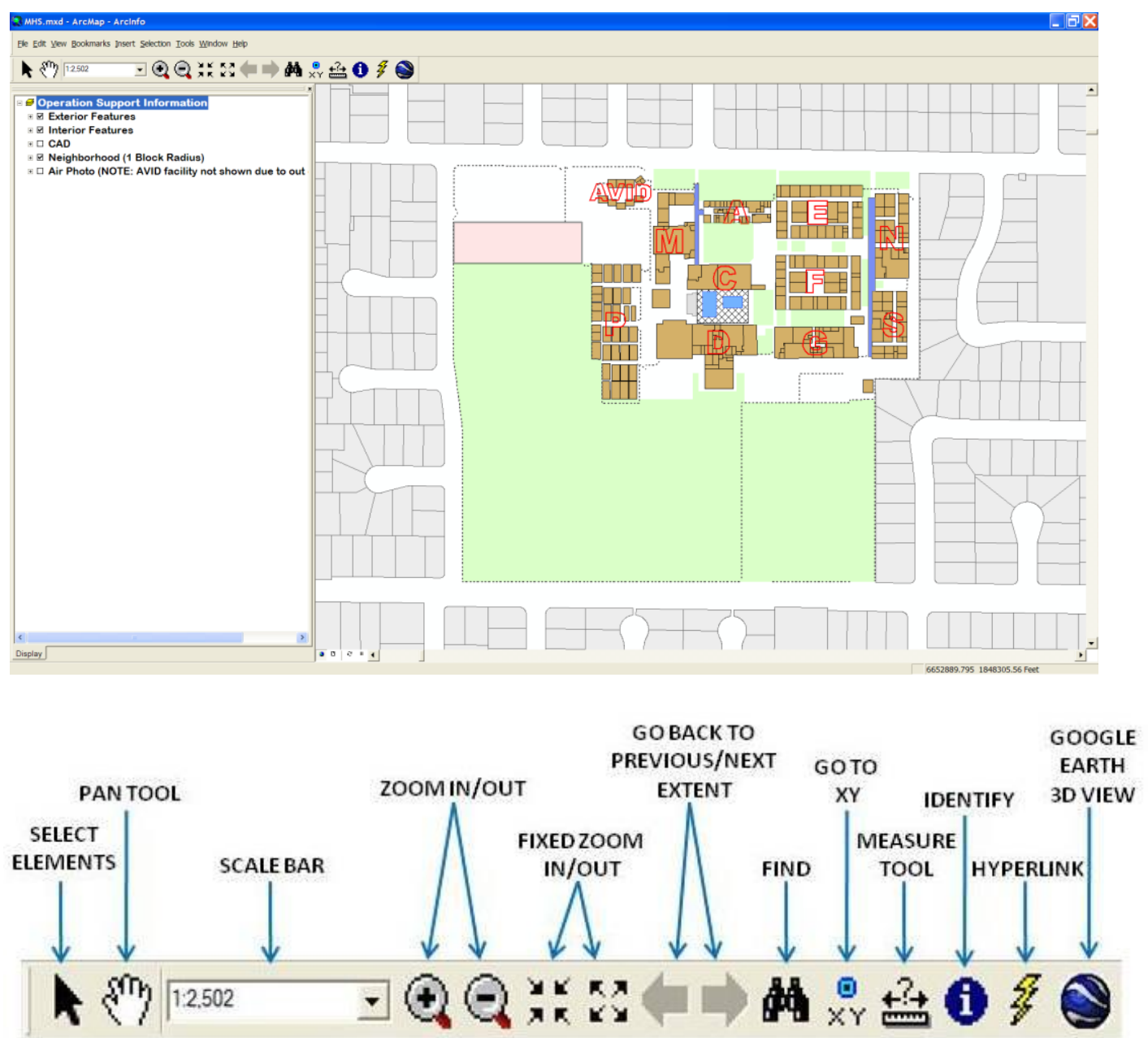

\section{MHS_ER Toolbar Tutorial}

6. On home screen view, expand the Exterior Features layer and further expand Access

Points layer:

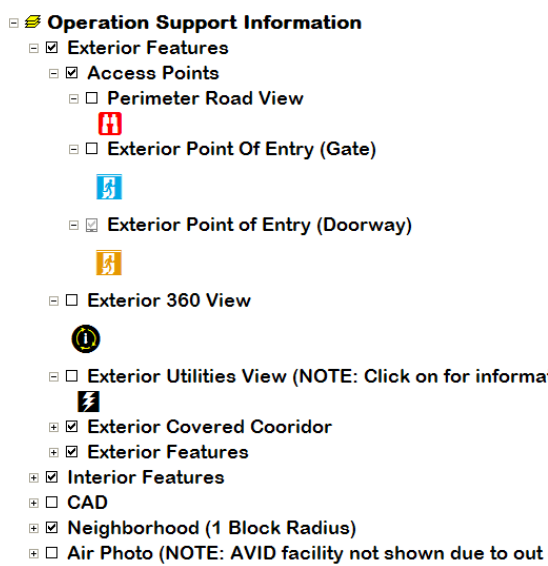


7. Check the boxes to activate Perimeter Road View and Exterior Point of Entry (Gate)

layers. Using the identify tool, select any Perimeter Road View point on the application to reveal an information box. The box reveals valuable information about the point. Click on the last row inside the information box to reveal a hyperlinked photograph of the point location. Do the same for an Exterior Point of Entry (Gate). Turn off the Perimeter Road View and Exterior Point of Entry (Gate) layers by unchecking the boxes.

8. Activate the Exterior 360 View and the Exterior Utilities View layers. Similar to Task 3, use the identify tool to select an Exterior 360 View point. (Note: the Exterior 360 View symbol consists of a black circle with three yellow arrows in a circular pattern to indicate a 360 degree photograph is associated with this point. The " $i$ " in the center of the symbol indicates that the point has an identify information box attributable to the point). After selecting a point, an information box appears with information about the point and a 360 degree photo hyperlink. Activate the hyperlink to show a 360 degree viewer. This viewer allows the user to pan and zoom in/out of the point location. Follow the same process to select an Exterior Utilities View point. The hyperlink for the Exterior Utilities View point will show a still photograph of the point location.

9. Using the zoom in tool, drag a zoom box around Building G. A close-up of Building G will appear. A number of symbols will display because of the zoom. All of these symbols indicate a different feature and each of which is scale dependant, which means that they will not appear until zoomed in to a specified scale. For the purpose of this specific testing, select an Exterior Point of Entry (Doorway) point using the identify tool. An information box appears with attribute information and a hyperlink option. Activate the hyperlink to reveal a still photograph.

10. Use the tool to return to the previous extent of the application, or the Montclair High School overview. Use the zoom in tool and drag a zoom box around Building M. This will zoom into the Auditorium and associated facilities. Notice that the interior symbol features are automatically activated. Expand the Interior Features layer as shown below.

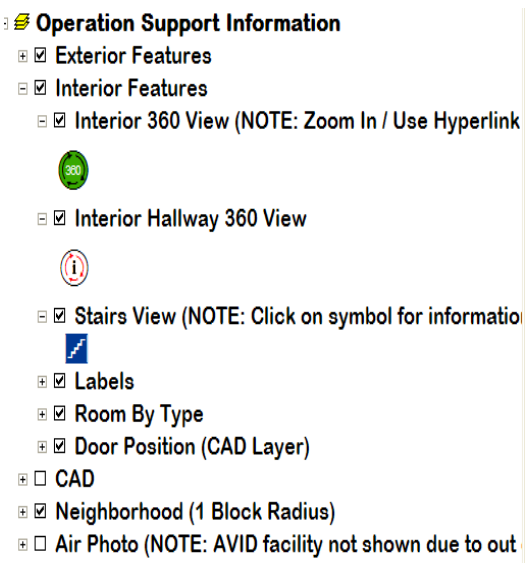


11. On the MHS_ER toolbar, select the $\bar{\xi}$ tool. Notice that a small colored dot is centered on the Interior 360 View points. This indicates that the hyperlink tool is activated and these points contain a hyperlink that is directly accessible by a click of the $\bar{F}$ tool. Select the point that is located in the Auditorium Upstairs Storage. A 360 degree viewer automatically appears showing the facility.

12. Continue to remain at this zoom level and location. Using the identify tool, select the Stairs View that is attributable to the Auditorium Upstairs Storage. Upon selection, an information box appears. Notice the attribute information and hyperlink. Select the hyperlink row to reveal a photograph of the stair location. Close photo and information box.

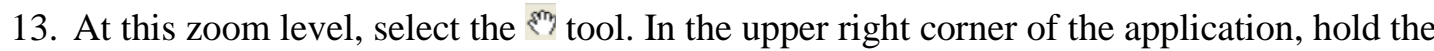
left mouse click and drag to the bottom left to reveal the zoomed in view of Building A. One unique feature that is displayed is the Interior Hallway 360 View. Similar to the Exterior 360 View mentioned earlier, the symbol for the Interior Hallway 360 View represents a point that has point information and a 360 degree viewer. Using the identify tool, select the Interior Hallway 360 View point to activate the box. Activate the hyperlink to reveal the 360 viewer.

14. Notice the odd colored lines that exist below the brown polygons. These lines represent CAD drawings for the school. The rationale for the CAD drawings representing an interior feature is to show the user the door positions for each interior facility or room. Deselect all the Interior Features layers, except the last one titled Door Position. This will reveal the CAD drawing for a much better view.

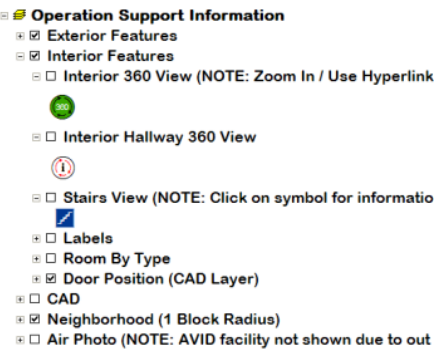

15. Although the CAD drawings listed under the Interior Features layer are scale dependent, the option exists to have a separate $C A D$ layer activated. Select $\rightleftharpoons$ tool twice to return to the main overview. Make sure the Interior Features layer is deactivated, and now activate the $C A D$ layer to reveal the CAD drawings for the school.

16. Now activate the Air Photo layer to reveal the air photo for the Montclair High School and its surrounding environment. This gives the user a completely different visual of the site.

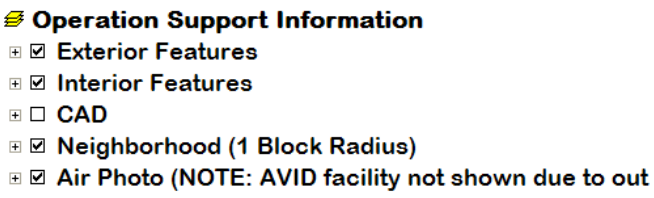


17. With the Air Photo layer still activated, use the $\rightarrow$ tool to draw a zoom box around the football field in the lower central part of the school campus. After zooming in, + t tool to measure a horizontal line from "goal post" to "goal post" (thicker vertical lines on both sides of the field). The end result should be around 120 yards. Before clicking on the point of your measurement, you can change the distance by clicking on the small down arrow on the measure box. This was designed to demonstrate the accuracy of the measurement tool on this application.

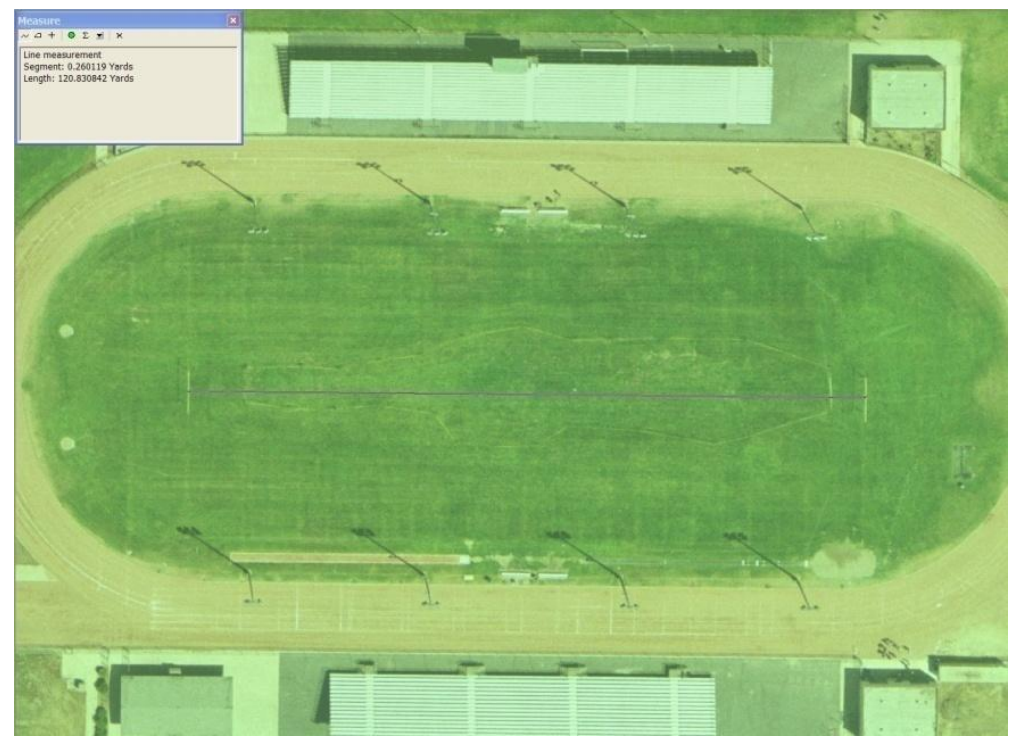

18. The final test is to activate the Google ${ }^{\mathrm{TM}}$ Earth link to reveal a custom made threedimensional visualization (3D) of the Montclair High School. Select the Google ${ }^{\mathrm{TM}}$ Earth button to activate the $3 \mathrm{D}$ view of the high school. The application automatically opens Google TM Earth and zooms into the Montclair High School. The user can zoom in/out and pan around the site in a $3 \mathrm{D}$ environment.

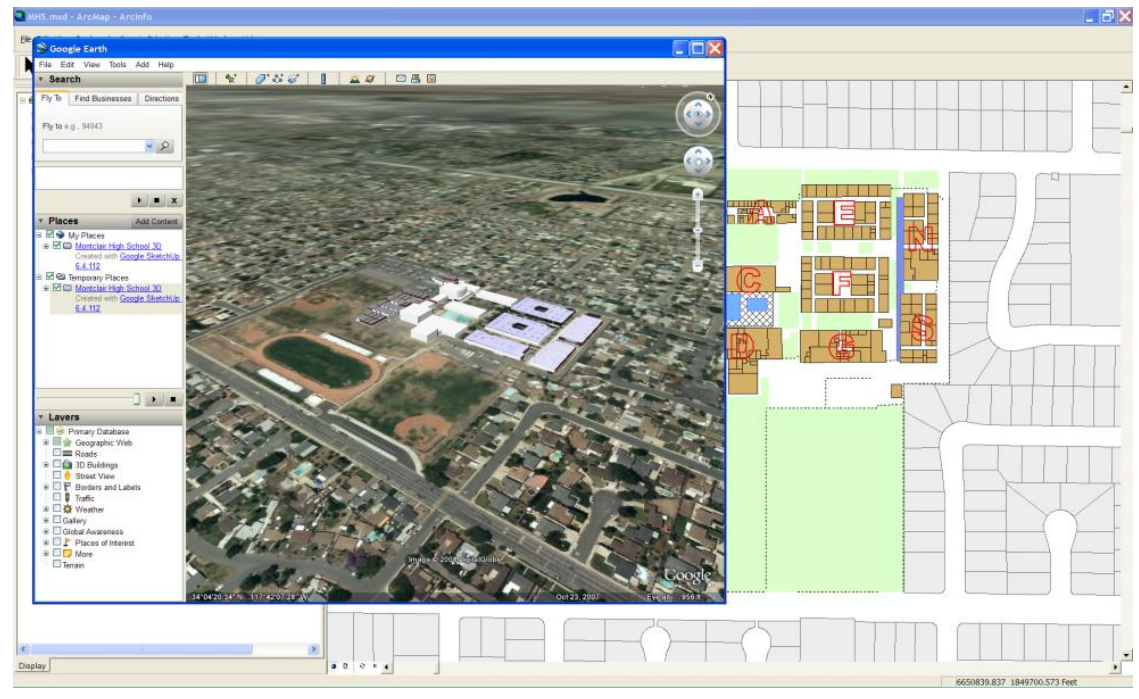


This concludes the testing tutorial for the Montclair High School Emergency Response GIS application. Thank you very much for taking the time to complete this tutorial. Please address any questions or concerns to the below email address.

H. Russell Johnson

University of Redlands MS GIS Program

howard_johnson1@ @redlands.edu
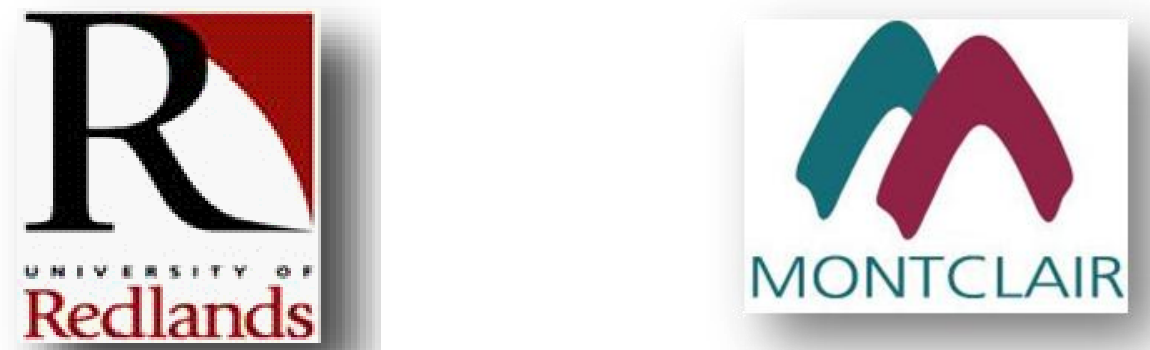


\section{Appendix B}

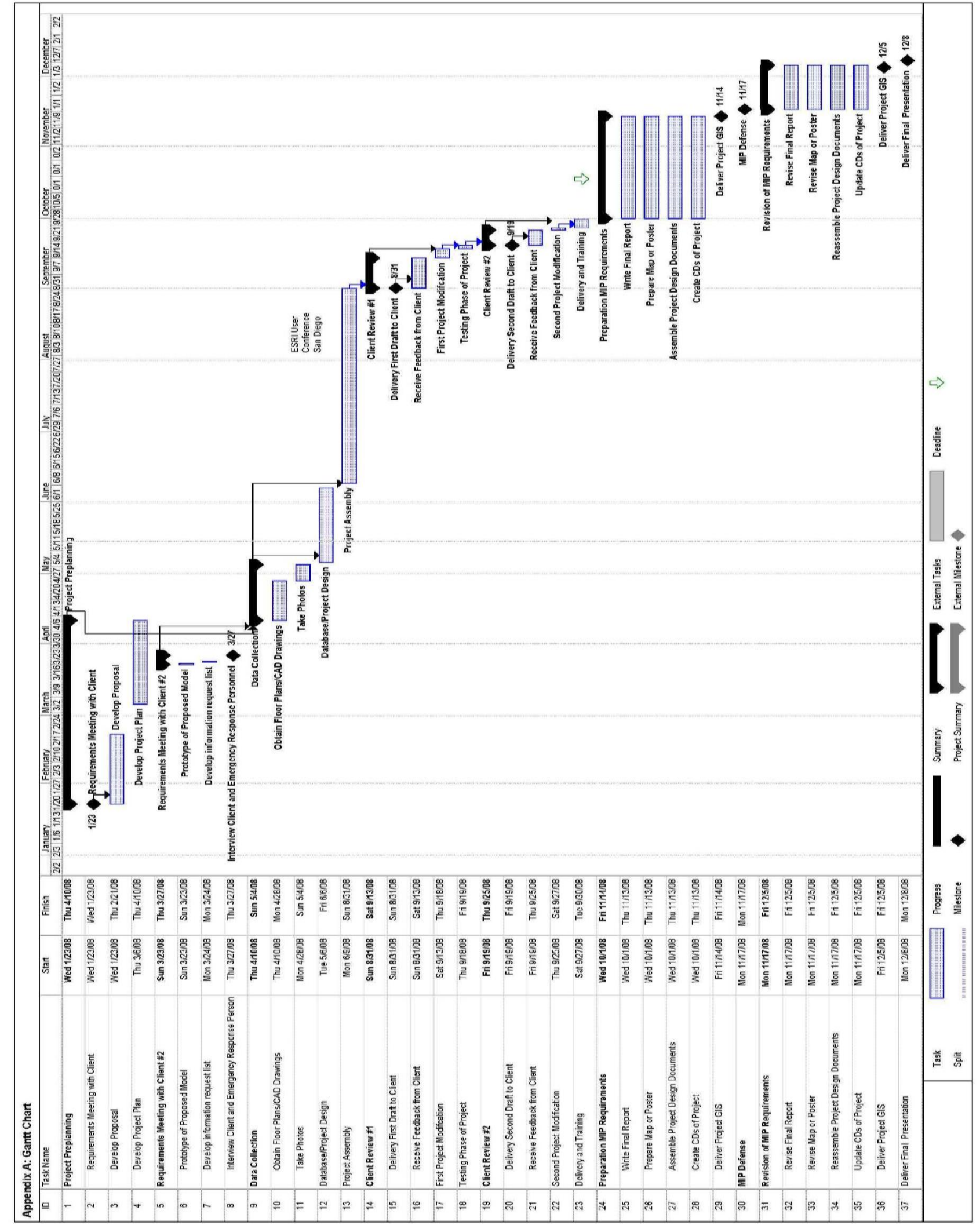

Appendix Figure 1. Gantt Chart 
Visual Basic code for Google ${ }^{\mathrm{TM}}$ Earth link

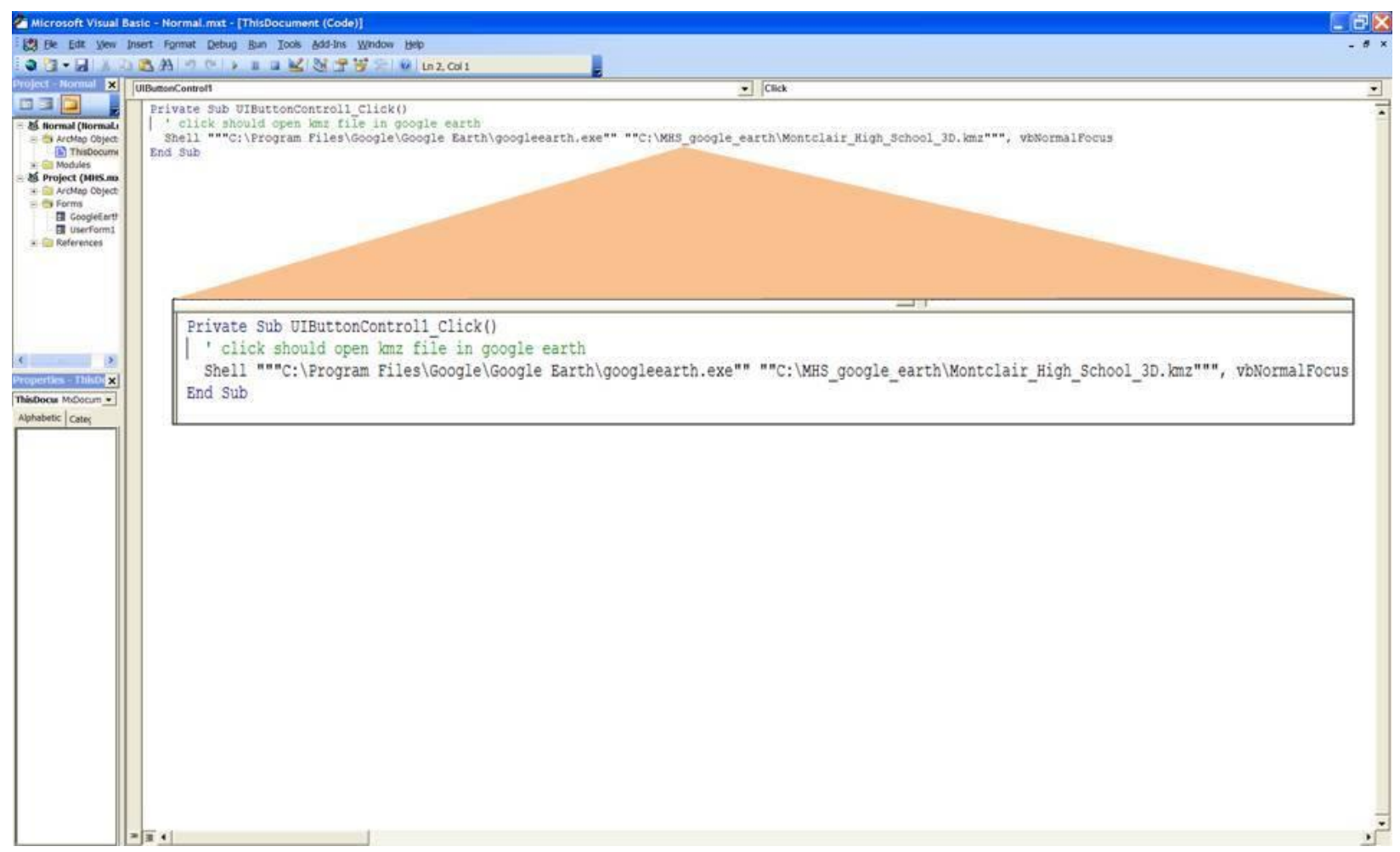

Appendix Figure 2. Visual Basic code for the Google ${ }^{\text {TM }}$ Earth link 